San Jose State University

SJSU ScholarWorks

Master's Theses

Master's Theses and Graduate Research

Summer 2012

\title{
Beating The Odds? An Analysis Of Dialectical Tensions Experienced By First Generation College Students
}

Laurina Jane Lanham

San Jose State University

Follow this and additional works at: https://scholarworks.sjsu.edu/etd_theses

\section{Recommended Citation}

Lanham, Laurina Jane, "Beating The Odds? An Analysis Of Dialectical Tensions Experienced By First Generation College Students" (2012). Master's Theses. 4198.

DOI: https://doi.org/10.31979/etd.6mqt-eae8

https://scholarworks.sjsu.edu/etd_theses/4198

This Thesis is brought to you for free and open access by the Master's Theses and Graduate Research at SJSU ScholarWorks. It has been accepted for inclusion in Master's Theses by an authorized administrator of SJSU ScholarWorks. For more information, please contact scholarworks@sjsu.edu. 


\title{
Beating The Odds?
}

An Analysis Of Dialectical Tensions Experienced By First Generation College Students

\author{
A Thesis \\ Presented to \\ The Faculty of the Department of Communication Studies
}

San José State University

In Partial Fulfillment

of the Requirements for the Degree

Master of Arts

by

Laurina Lanham

August 2012 
(C) 2012

Laurina J. Lanham

ALL RIGHTS RESERVED 
The Designated Thesis Committee Approves the Thesis Titled

Beating The Odds?

An Analysis of Dialectical Tensions Experienced By First Generation College Students

By

Laurina J. Lanham

APPROVED FOR THE DEPARTMENT OF COMMUNICATION STUDIES

SAN JOSÉ STATE UNIVERSITY

August 2012

Dr. Deanna L. Fassett

Department of Communication Studies

Dr. Shawn Spano

Department of Communication Studies

Dr. Anne Marie Todd

Department of Communication Studies 


\title{
ABSTRACT \\ BEATING THE ODDS? \\ AN ANALYSIS OF DIALECTICAL TENSIONS EXPERIENCED BY FIRST GENERATION COLLEGE STUDENTS
}

\author{
By Laurina J. Lanham
}

Current scholarly research on first generation college (FGC) students is concerned with attrition rates of these students and other ways institutions of higher education count FGC students. However, much of this research focuses on negative characteristics (e.g., "at-risk," low income) often associated with the FGC student community. Not only do these reports exclude the success rates of FGC students, but they also overlook the other identities that these students experience, such as working class identity. We know little of how these students negotiate this identity in their communication with others and how this process affects their communication in college classrooms.

Using relational dialectics theory, this study goes beyond examining how many FGC students succeed in school by providing an in-depth examination into the experiences of these students. It is important to understand how FGC students navigate higher education and what actions they take that they feel contribute towards their success in or withdrawal from college. This study identifies three tensions that emerge for FGC students: predictability-novelty, autonomy-connectedness, and opennessclosedness. This study also analyzes the ways in which FGC students manage and negotiate these tensions. After discussing implications that these tensions have for FGC students, this study offers suggestions for students, educators, universities, and researchers to invite constructive ways to cope with these dialectical tensions as they emerge. 


\section{ACKNOWLEDGEMENTS}

To my advisor, Dr. Deanna Fassett, words do not suffice my appreciation for your support. Thank you for believing in this study and for believing in me and challenging me along the way. This writing would not have been possible without your guidance and help with editing along the way. You are a true inspiration and your mentorship empowers me as a student, teacher, writer, and as a person. Your lessons on the importance of self-care through this process are a true example of your critical yet compassionate approach to teaching and for that, I am a better person.

To my committee members, Dr. Anne Marie Todd, and Dr. Shawn Spano, thank you for your encouragement, support, and for challenging me. Your guidance has helped me make this document stronger, more insightful and more meaningful. I am immensely grateful for your contributions.

To my fellow FGCs, your determination brought you this far. Take great pride in knowing that you are the first in your family to embark on this path. Believe in yourself, aspire towards greatness and know that while failure will be part of the process from time to time, it does not define who you are as a person. Find comfort in knowing that you are not alone. Please accept this study as my small contribution towards a greater dialogue.

To Mary Anne, my dear friend and thesis-writing companion, I cannot believe we are here. I am so proud to share my accomplishments with you. Thank you for providing me a sense of calm through this process. Your guidance and support proved instrumental in my growth, thank you for believing in me when I did not always belief in myself.

To Tiffany, my colleague and friend, thank you for sharing your editorial expertise with me. Thank you for playing a part in this process and for reminding to take 
time to listen to the sound of birds outside my window, saying, "don't worry about a thing, cause every little thing is gonna be alright."

To my family and to Dino, thank you for your unwavering support and unconditional love. Your love and understanding throughout the course of this writing means more to me than you may know. I am forever grateful. 


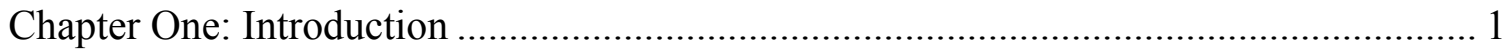

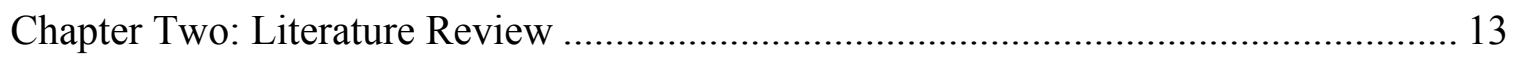

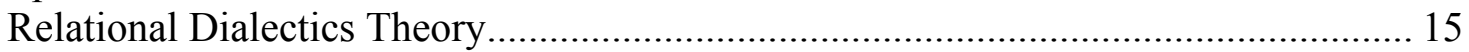

First Generation College Students and University Surveys....................................... 25

First Generation College Students, Identity, and Liminality ................................... 27

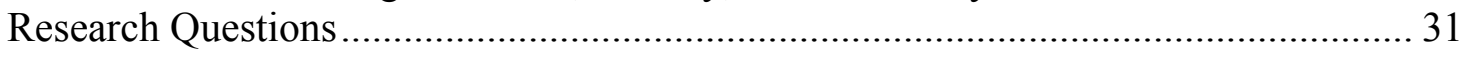

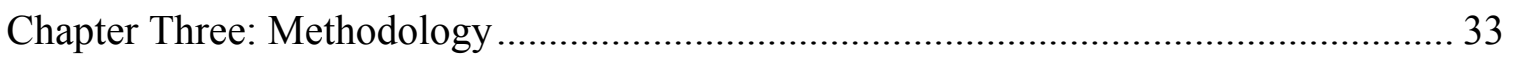

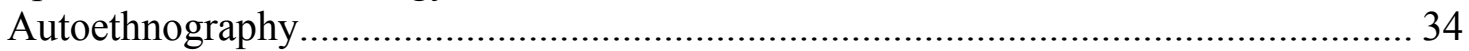

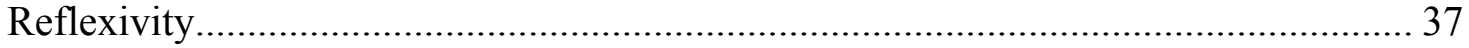

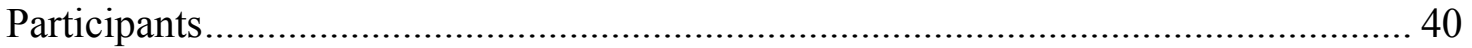

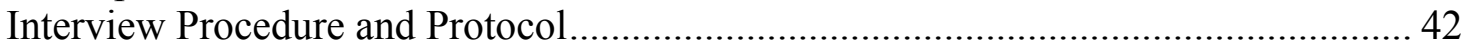

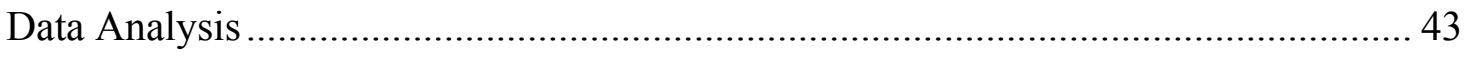

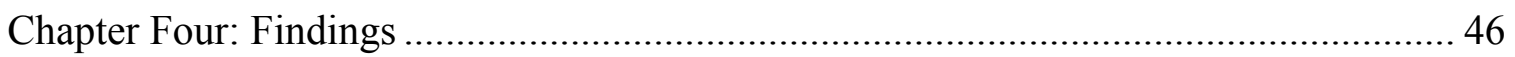

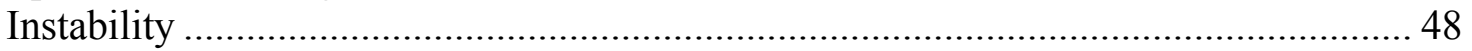

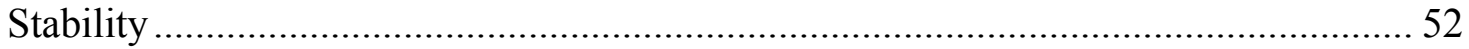

The Predictability and Novelty Dialectic......................................................... 55

Strategies for Navigating the Tensions Between Predictability and Novelty........... 58

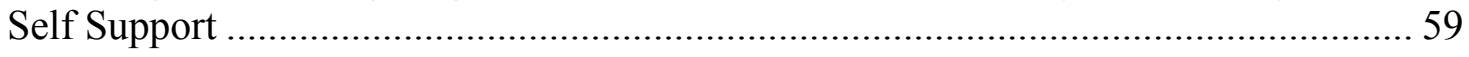

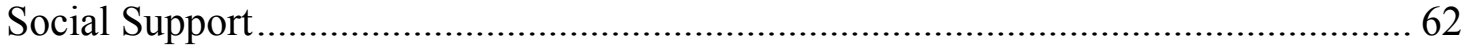

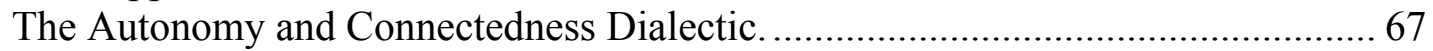

Strategies For Negotiating Tensions Between Autonomy and Connectedness....... 70

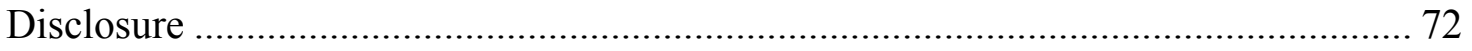

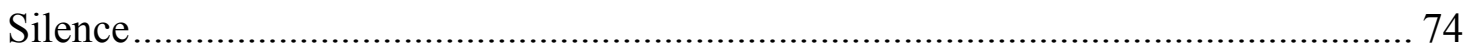

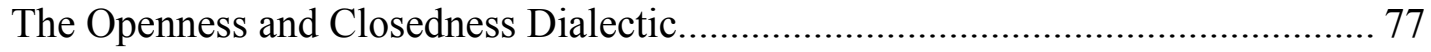

Strategies for Navigating the Tensions Between Openness and Closedness............ 80

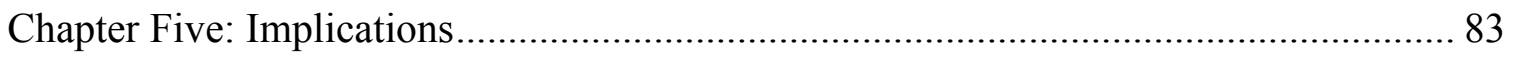

Implications and Recommendations for University Administrators ........................ 85

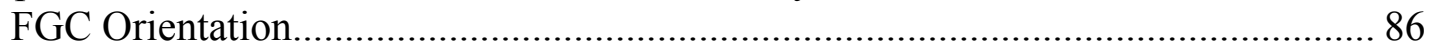

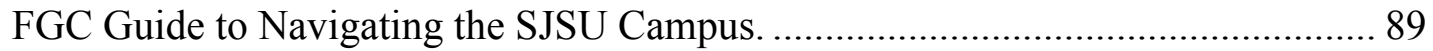

FGC Student Acculturation to College Life. ....................................................... 92

Implications and Recommendations for Educators .............................................. 95

Implications and Recommendations for Researchers ...................................... 100

Implications and Recommendations for First Generation College Students .............. 104

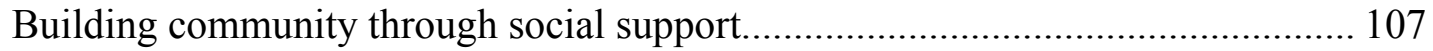

Building relationships with faculty through mentorship. ................................. 109

Building confidence by exploring campus recourses. .................................... 110

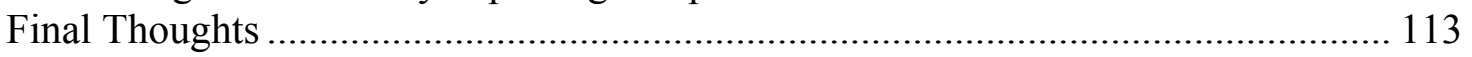

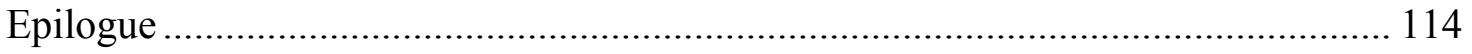

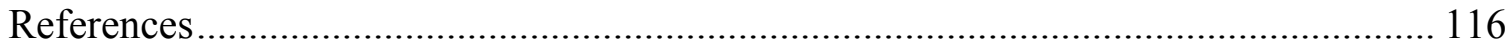

APPENDIX A: IRB Approval to Conduct Research.................................................. 120

APPENDIX B: Agreement to Participate in Research ................................................ 121 


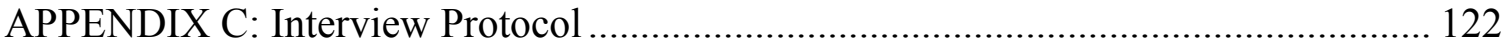




\section{Chapter One: Introduction}

Like any other day, I am seated in my chair at work, staring at a screen full of emails wondering how I am going to respond to all of them in a timely manner. I feel empty. Three years have passed since I received my undergraduate degree, and I am not in the place I thought I would be. How did I get here? Oh, I remember, I just needed a job. So, here I sit, at my job, yearning for more. I come back to my computer screen, begin to respond to emails and remind myself to be thankful for the fact that I have a job. It is at this moment the phone rings; it takes me a moment to realize it is mine. "Hello? Yes. This is Laurina." I pause and wait for the voice on the other end to continue. The call is brief and the voice on the other end, though unfamiliar, has a friendly demeanor. I quickly realize that this is the call I have been waiting so long to receive. I hang up and sit back in disbelief: I got in? "I GOT IN!" Though the call is brief, the exchange is a pivotal moment in my life. I do not know it at the time, but I am about to embark on one of the greatest and most difficult journeys of my life.

It has been a while since I was back in school; the room is familiar, the chairs are familiar, but the stakes in this space are much higher than they were when I first joined this community. As I take my seat, I silently hope to myself that no one notices I slipped through the cracks. I never thought this was possible: would I really be the first person in my family to do this? I am reminded that I am part of a generation of students that is showing up knowing that those before us could not. Each time I show up, feelings of uncertainty fill me; I am here, I made it, but do I belong? I'm not sure yet. I will have to wait and see. 
I am embarking on a journey, an uncharted path. There are no markings, no signs indicating that those who came before me traveled down this same path. For a moment I feel alone, then I hear voices on either side of the path; they are voices of support, telling me how proud they are of me, so I continue to move forward. But I am afraid and feel a weight that I have never experienced. This weight is the pressure I have now put upon myself to succeed. Even as I write this, I still experience feelings of inadequacy. The journey is coming to an end, so I quickly remind myself that I cannot take this opportunity for granted.

The phenomenon of first generation college students is not a contemporary one; however, it is difficult to find a large body of research that looks at the origin of the title or when it became a recognized identity marker within the college culture. Getting the word out about first generation college students has been slow moving, and some institution officials are still unfamiliar with the term; it is, in essence, a newer construct (Davis, 2010, p. 1). According to Davis (2010), most institutions do not even count how many first generation college students they have. He attributes this to confusion surrounding the definition of what exactly a first generation college student is.

At present, FGC students are increasingly enrolling at college campuses across the United States. Davis (2010) reports that over 40\% of FGC students are incoming freshmen. However, much of the research looks at counting students, quantifying them into check boxes on surveys that force students to choose only one identity marker, representing a part of the student "self" that overlooks all of the other factors that contribute to FGC student status. Billson and Terry (1981) defined first generation college students as those whose parents have had no college or university experience. In 
other words, these students are the first in their families to pursue education beyond high school (p. 35). Alternatively, TRIO programs (Upward Bound, Talent Search and Special Services for Disadvantaged Students) sponsored by the U.S. Office of Education use a definition derived from Fuji. A. Adachi in his unpublished paper "Analysis of FirstGeneration College Student Population (A New Concept in Higher Education);” for these programs, FGC student status applies only to those students who do not have at least one parent who is a college graduate and is one factor in conjunction with low income status for determining a student's eligibility for TRIO programs (Billson \& Terry, 1981, p. 35). According to Davis (2010), admissions officers and administrators at universities prefer to have only one definition: individuals can claim first generation college student status if neither one of their parents or guardians possesses a four-year college degree (p. 2). For the purpose of this research, I used Davis's (2010) definition; neither parent or guardian possesses a four-year college degree.

It is important for the students, the faculty, and the administrators to be able to have one definition so that they do not feel as though "anyone" is a FGC student. Removing the vagueness will allow FGC students to receive more attention because it will be clear who is a member of this community and who is not. Few studies invite a dialogue from the perspective of the student, on how FGC students negotiate tensions of identity in the college classroom. Qualitative studies, primarily through interviews with FGC students, focus on salience (i.e., how well a FGC student adapts to a classroom compared to a non FGC student) (Orbe, 2004), assimilating to a new culture (Orbe \& Groscurth, 2004), and attrition rates for FGC students of color (Putman \& Thompson, 2006). 
There is no extant research regarding the success rates of FGC students as they matriculate from the maze of higher education due, in part, to how the universities count these students. FGC students are enrolling in universities at increasing rates and research suggests that these students are more likely to drop out or take longer to graduate than non-FGC students, should they choose to continue their education (Davis, 2010). Though this student population has always been present, it has only recently received acknowledgement from universities. However, much of the research on FGC students' focuses on negative characteristics (e.g., "at-risk," low income) often associated with the FGC student community. Davis asserts that the negative characteristics associated with FGC student bodies should not define these students.

In addition to reporting that excludes the success rates of FGC students, the multiple identities, such as working class, that these students experience is also overlooked in such reports. "It behooves educators at American postsecondary institutions to work harder toward making such [negative reporting] less common" (Davis, 2010, p. 1). We know little of how this aspect of identity is negotiated in their communication with others (Orbe, 2004), and we know even less about how these students negotiate the implications of social class in the classroom. We know little about how FGC students negotiate, in their communication with others, multiple identities in the classroom. FGC students, whether undergraduate or graduate, experience moments where they are in a liminal space, or "betwixt and between," a transitional period from one social status to another (Turner, 1987). 
How is it that I am in college and I struggle so much with writing? Why does it take me so much longer to write papers and edit than my classmates? I hear them come into class bragging about how easy the assignment was and all I can think about is how many sleepless nights I spent trying to sound educated in what I was writing. I have no frame of reference for college; no one taught me how to be in college; so I feel like I have to overcompensate and end up spending way too much time trying to prove that I know what I know instead of just saying it. I think it might help if I could see an example of what a college paper is supposed to look like. What are the teachers' expectations? Will I have to fail before I can succeed?

As a FGC student, I experience multiple tensions in the classroom and in trying to navigate the university. Up to the point of receiving my undergraduate degree, I was the first in my family to attend college. While in the process of receiving my degree, my mother and stepfather enrolled in college to further their careers. Several nights a week we would all sit around the kitchen table and write papers, discuss class work, and agonize over the rigor of college. These nights were a comfort to me because, for the first time, I was not the only person in my household pursuing a college education. Though I was able to experience these feelings with my mother and stepfather, under Davis's (2010) and Orbe's (2004) definitions, I am still considered a first generation college student because I was the first in my family to enter college and receive a degree. Additionally, my father does not hold a four-year college degree. I found myself caught in a liminal space of being able to relate my experiences in college with those of my mother and stepfather, but experiencing frustration and discomfort at not being able to share those same feelings with my father. I would often avoid discussing my studies with 
my father because I began to recognize the opportunity I was afforded. He was not able to attend college; at least I don't think he was. Perhaps he did not want to go and that is what has led to my reluctance to share my experiences with him. I have always felt as though I was talking to him about topics he might not be able to relate to, and I have wanted to spend my time with him in ways that would not point out my educational journey because perhaps it was not as interesting to him as it is to me.

I am one of many FGC students in my graduate school cohort; each of us shares the experience of coming from families who have little, if any, understanding of what it is like to be a college student. Orbe (2004) asserts that even within this group, we tend to draw distinctions between FGC students who enter college from nontraditional, disadvantaged backgrounds and those who come from families with considerable social capital. This is to say that, in the absence of college-educated family members, these students still experience significant support in the home, more so than those students from non-traditional FGC student backgrounds. Although first generation students are privileged in that they are able to attend institutions of higher education, there is also a feeling of disadvantage; they are in a liminal space between the opportunity to attend college and not having someone in their family to relate to their experience. Davis (2010) asserts that access to higher education in the United States is getting easier for many people. From 2000 to 2015, there has been an increase of about 4.9 million, in the number of students who enrolled in post secondary education, while admission rates are increasing; the number of students who stay in college is decreasing by 8.3 million (p. 12). What Davis does not say is that attending college is a privilege, regardless of one's educational background or that of those who came before her or him; education is 
accessible to all but not always attainable. While students might be able to get into college, it is what happens while they are there that makes higher education inaccessible to some. hooks (2000) tells us that FGC students occupy an odd positionality between privilege and oppression. I have experienced this first hand during my time in graduate school—much more than I did as an undergraduate. Often, FGC students who enter college are the first in their family to do so; therefore it is a kind of acculturation. FGC students begin to acculturate into a community outside of their household. The experience of registering for classes, purchasing books, and sitting in college lectures for the first time is likely unfamiliar territory. College is one world, and home is another; often FGC students see these as separate; for these students, sharing experiences of college at home is often not an option.

Orbe (2004) asserts that ongoing negotiation of home and college life results in students trying to live liminally between what often is two vastly different worlds, causing FGC students to feel like outsiders at school as well as at home. I experienced a sense of pride knowing that I would be the first in my family to earn a college degree, giving rise to a large amount of pressure on myself to not disappoint anyone. I did not give a great deal of thought about what "label" I would take on when I joined this culture. I was not sure what my identity would be in the classroom.

Learning how to adapt to meeting the rigors of higher education is part of the orientation into a new community, however this does not mean that all students should have to experience struggle in becoming acculturated to college life. It was not until I began graduate school that I realized how much the binary between school and home affected me. In the classroom, I have suffered feelings of inadequacy, and though I was 
accepted into the program, I could not help but look around at all the other faces in the room and measure my worth as a student against theirs. At home, I began to isolate myself because I was in a place academically that I had not been in at any other point in my life. Although, I was proud of the accomplishment of entering graduate school, I was also greatly humbled and was careful to avoid appearing "above" anyone else in the household. Though these spaces were new, I was also for the first time in my life humbled by the newness of being one of the few students in my graduate cohort to hold a full time job. Learning how to shift between these identities has greatly affected my experiences in graduate school and is a part of my identity as a first generation college student. I have spent my days at work striving to prove that I could still do my job, even though I am in school. I have spent my nights in class trying to prove to myself, my teachers, and my cohort that even though I am a FGC student, I can still succeed. I have spent my weekends trying to avoid having to tell my friends and family that I could not spend time with them because I have school work to complete; I am not sure they would understand, and this is a very large part of why my identities as a person have been in flux.

I did not enter graduate school labeling myself as a first generation college student, nor did I have prior knowledge that a FGC student community existed in universities. I honestly never gave it much thought; it was not until reading an article by Orbe (2004) that this became a visible identity. I originally read this article because it addresses the intersections of multiple identities on a pedagogical level. This is a body of research that has always been of interest to me. It is incomplete to look at just one aspect of a person and make assumptions about his or her life. By acknowledging multiple 
identities, which play conflicting roles into the realities of college students, Orbe makes visible the prevalence of first generation college students in higher education. I believe that in order to fully understand a person, we have to look at all the components that make her/him who s/he is and recognize that each intersects with one another.

Aside from Orbe (2004), there is a lack of extant research surrounding the multiple identities of FGC students. I assumed that I was one of the few students in my cohort who was experiencing feelings of being the first in my family to pursue higher education and, as a result, I was overly shy about letting anyone know that I am a firstgeneration college student. I am not just a first-generation student though, I am also a full time student (e.g., carrying 8 units or more per semester), I hold a full time job so that I can support myself, I am a 29 year old female, I belong to the lower middle class, my family is of Portuguese decent but resides in the U.S, and I am a graduate teaching associate. According to Davis (2010), in his analysis of FGC students, my success in academia thus far, as an FGC student, is, in a way, beating the odds.

In addition to all of the different possible identities a FGC student has, Davis (2010) asserts that FGC students often enter the classroom as working class students, meaning that they are negotiating their time at school with employment so that they can pay their way through school, save money to pay down loan debt, purchase books for school, or simply live. I have many conversations with fellow FGC students in my cohort who voice frustration to me regarding having to compromise their jobs in order to succeed in school, or having to compromise their school work in order to keep their jobs. I hear these stories and it reminds me of my experience in college, as an undergraduate student, and also as a graduate student. Identifying as a FGC student, and also as 
working class, changes the student experience. Social support plays a large role in how FGC students learn to negotiate and cope with tensions that arise in a college classroom. Quite often, we are not able to build a social support system with our classmates because we are working before and after school and are not able to grab lunch after a class is over, or meet before class to become better acquainted with one another. In my experience, I have felt very isolated as a student, watching my classmates discuss their plans for the day, considering together whether to study or listen to a guest speaker. I was headed to work; my homework and socializing would have to wait for the weekend.

While driving to work, I would grapple with whether or not I would be able to be a visible member of my graduate cohort because I was only on campus for my classes. I began to feel like I should be at school while at work, and at school, I had anxiety about what might be going on at work. This is an ongoing negotiation. Feeling like there is not enough time, wondering how I am going to meet deadlines at work and deadlines for my classes...these feelings have not gone away as I have progressed through the program. I imagine it will not go away, and I am not certain that I want it to, because it feels as though that would mean I would have to choose and I am unwilling to make a choice. As a result, I continue to do what I can to stay afloat in both areas of my life, but the feeling of wondering whether I will be able to fully succeed as a working class first generation graduate student continues to loom over me. As I grow closer to the culmination of my studies as a graduate student, I am reminded that every experience I face, every liminal space I am caught in, is all a part of how I make sense of who I am, who I will become, and where I have been throughout my life - most of which has been spent in college as an FGC student. 
Exploring my journey has not been easy. I have dealt with many uncomfortable moments when writing this thesis. It was not until embarking on this research that I realized why I experienced these feelings. For much of my college career I felt like I had to choose; I did not know how to live harmoniously with colliding identities. I did not know where to go for support, and I was leery of discussing these feelings with anyone because I did not want to appear weak or incapable of meeting the rigors of college. So, I remained silent when I should have been speaking with others. I should have been creating meaningful dialogue with other members of my cohort. But, I did not; silence prevailed.

It is imperative to gain a more complete understanding of FGC students, and how, through relational dialectics, we can gain a better understanding of how students negotiate liminal spaces and manage multiple identities. Through this approach, we can better understand how FGC students navigate and can overcome these challenges and succeed in a college classroom. This study examines current research on first-generation college students for how first-generation college students experiencing identity negotiation, and how, through social support and relational dialectics, we can learn how to negotiate these tensions as liminal spaces that pose flexible possibilities instead of either/or choices. I look to Baxter and Montgomery's (1996) concept of relational dialectics as a useful tool for gaining a deeper understanding of how FGC students negotiate and manage tensions associated with multiple identity roles. Baxter and Montgomery offer a meaningful way of looking at multiple dimensions of identity; in their research, they persuade us to hold on to these tensions as a way of creating more holistic relationships. This is achieved by "satisfying oppositional demands," through 
relational dialogue. The belief that relational well-being is made possible by our ability to "achieve 'both/and' status" within our relationships (p.6).

The goal of my research is to illuminate and explore the dialectical tensions first generation college students experience in higher education as they negotiate identity management in the classroom. Through autoethnography, I wish to enter an ongoing conversation about first generation college students' success in higher education and better understand the ways in which, through narratives, FGC students negotiate identity related tensions. In this, I mean to be reflexive, using personal experience as a way to explore and address social inequities in the academy. I will uncover the implications and propose strategies that invite the academy to create resources for FGCs as they enter college for the first time. Furthermore, I will to discuss specific strategies FGC students can use to manage these multiple identities

The purpose of my study is to go beyond examining how many FGC students succeed in school by going in depth into the experiences of these students to understand how they navigate higher education and what actions they take that they feel contribute towards their success in or withdrawal from college. Through this study, I hope to learn about how other first generation college students negotiate dialectical tensions in the classroom, and the ways in which these tensions might play a role in their ability to succeed in higher education. I am also interested in gaining a more clear understanding of the ways in which FGC students' access to navigating college contributes to success in higher education. 


\section{Chapter Two: Literature Review}

Every year, students apply for college. It is a ritual of sorts; they send in their applications to numerous universities, hoping they will receive at least one acceptance letter. For some, this is a rite of passage in their families, as they often apply to universities that other members of their family attended. Other students do not even know where to start. I was one of those students. The college application process seemed daunting to me; I did not know how to navigate the system, and I was even more concerned with how my acceptance to a university would affect my family financially. Because of these feelings, I chose to bypass the application process altogether and attend a community college. It was a much less intimidating transition for me, and carried much less of a financial impact on my family than going directly to a university. After attending community college, I made a seamless transition into a traditional university; from there, I was accepted into graduate school. Prior to acceptance into graduate school, I did not give much thought to my identity as a student.

My family boasts that I am the first to pursue a college education. However, I gave very little consideration to how this would shape my reality as a student, and as a result, I experienced feelings of extreme pressure to succeed. The thought of letting anyone down almost interfered with my ability to succeed. I made the college experience difficult for myself because I was overtaken by fear, afraid to ask questions, and spent a great deal of time trying to understand how to navigate the system. As I progressed in my studies, I began reading research about first generation college students, and I found myself relating to some of the research, but not all of it. A lot of research surfaced statistics on a FGC student's ability to succeed in higher education, while other research 
focused on the drop out rates of FGC students. I yearned for more studies on the identities of FGC students and the correlation with attrition rates. I wanted to know more about how these students were succeeding and what contributed to their success. Current research tends to focus on the relationship between a student's status as a first generation college student and whether or not s/he will successfully complete a bachelor's degree or go on to enroll in graduate school (Orbe, 2004).

Since much of the research on FGC students focuses on attrition and success rates (Davis, 2010), I began to see a need to expand on this research and look at the person behind the FGC status, in order to gain a full understanding of how s/he negotiates multiple identities, and how this occurs inside and in relation to a college classroom. With each year, there is an increase in FGC students enrolling in universities (Davis, 2010). The ongoing conversation in this body of research needs to include the importance of understanding the tensions and challenges that are rife within college classrooms. Davis (2010) asserts that the foundational study presented in his research dates back to 1989. According to the National Center for Education Statistics (NCES), $43 \%$ of all beginning postsecondary students who entered college in the fall semester of 1989 had first generation status. Although the study is dated, Davis states that researchers investigating FGC students in higher education look to this study as groundwork for establishing national statistics (p. 11). I see the utility in the statistical data as foundational groundwork for how to count FGC students; however, I cannot help but acknowledge what this research does not tell us. I wonder about the social class standings of these students, I wonder about the bodies behind the data, such as the ethnicities, sexes, genders, and (dis) abilities of these students. Statistical data does not 
provide this kind of information within the parameters of this particular study. Although it provides a place to start, it is more than two decades old and not inclusive enough for examining the types of students who come to identity as FGC status as well as how this identity plays a role in their experiences in higher education.

Many institutions use support programs to improve academic success rates for FGCs. However, these programs often result in particular students feeling isolated or removed from the non-FGC student population on campus; some worry that these students never fully integrate into campus culture (Lowry-Hart \& Pacheco Jr., 2011, p. 55). Current research on the communication needs of first generation college is growing; however, existing research lacks depth, insight, and awareness of hegemonic class divisions, along with divisions within the institution, specifically in college classrooms. Furthermore, studies that examine identity management in first generation college students are sparse (Orbe, 2004). In this review, I will explore current research by providing a framework for how relational dialectics theory is a useful tool for analyzing the liminal tensions that play a role in the identity(s) of FGC students. Relational dialectics theory suggests that relationships are in constant motion, a give and take. This framework invites exploration into current FGC research, focusing on two themes: FGCs and university surveys and FGCs and identity management. I will conclude by illuminating how my dialectical study of FGC students goes beyond current understands of the FGC community.

\section{Relational Dialectics Theory}

Dialectical tensions are liminal spaces, where one feels these "in between" opposing mindsets. I experience this frequently as I balance time between school and 
work and negotiating how to provide the appropriate amount of time each of these opposing identities (e.g., full time student and full time worker) requires. Prentice and Kramer (2006) note that language and meaning created between people is in the interplay of these two opposing forces (p. 340). Baxter and Montgomery (1996) offer another approach for addressing dialectical tensions, asserting that the concept of opposing forces allows recognition of people in relationships as being pulled in many different directions that cannot be resolved. A similar experience exists for FGC students negotiating multiple identities. Students shift between wanting isolation and needing social support, some shift between student and worker; attending school full time and working full time, and some shift between feeling heard and feeling silenced in a classroom. It is these internal tensions, these opposing relationships between self and other, that warrant the use of relational dialectics theory in my research. This is useful because it will illuminate unacknowledged class systems that permeate Western society, by looking at the fundamental motivation to keep people disadvantaged, other-ed, and marginalized. Relational dialectics will facilitate a more nuanced understanding of the identities, experiences, and communication needs of first generation college students.

Lowry-Hart and Pachecho Jr. (2011) use relational dialectic theory to explore FGCs in relation to intercultural communication; specifically, they look at intergroup and outer group communication on college campuses, aiming to help colleges create a more inclusive environment for FGC students. Lowry-Hart and Pacheco Jr. broadly examine college settings and the ways in which this is a factor in a FGCs ability to succeed. While universities systems play a large role in the experiences of FGCs, it is imperative to also dissect all element of the identity of the FGC students who are attending 
universities and how these identities, specifically one's social class standing help shape their response to campus culture. Using Baxter and Montgomery's (1996) framework, Lowry-Hart and Pacheco Jr. discovered two themes in their research: intra-individual tensions versus inter-group tensions and compared the differences between the two. Their research was helpful for me because it allowed me to understand the importance of using relational dialectics theory when approaching FGC research; however, it also caused me to reflect on my experiences as a FGC student and while much of their findings hold true, I wanted to explore FGC student experiences through the lens of my personal experience in relation to what other FGC students are experiencing. I wanted to explore relational dialectics, but I also wanted to understand more about the actual students themselves, not just about whether or not they fit into college, but the reason why they did not fit into college. According to Lowry-Hart and Pacheco Jr. (2011), as FGC students negotiate their place in college, they must minimize their interactions with peers, professors, and others. Students in their study shared that they would go to class and then leave because they did not understand the "college experience" outside of class and these students had not yet established peers to help them negotiate this dialectical tension (p. 59). This spoke volumes in terms of what it can be like for FGC students in the classroom, it also reinforced the importance of using relational dialectics theory in my study. Lowry-Hart and Pacheco Jr.'s study provides a useful platform from which I can approach my research.

From a relational dialectic standpoint, Baxter and Montgomery (1996) share several strategies that people can use to negotiate complex dialectic dialogues. The strategies are denial and disorientation, spiraling inversion, segmentation, balance, 
integration, recalibration, and reaffirmation. Denial speaks to the tendency to subvert the existence of contradiction by viewing items from a single lens, ultimately ignoring any other viewpoint. I experienced a great deal of denial in my first semester of graduate school. I was not ready to hear what others had to say about their perspective on choosing to work while attending graduate school, and what that might mean for my ability to find time for both my course work and my workload at my job. Disorientation is a label the authors give to those who are unresponsive to change, feel trapped, or are unable to make a decision between two tendencies. As a result, oppositions are blurred, creating disorder and disorientation. During the second semester of graduate school, I developed feelings of isolation because I found myself in a place where my social circle was dissipating and my school work became so much that I felt trapped between wanting to reach out for support and feeling too much pride to admit that I may have been over my head. Spiraling inversion speaks to tendencies that are more prevalent than others at a given time, shifting privilege toward the dominant tendency. While I did make the decision to keep my job while attending graduate school, I could not help but experience waves of intermittent envy towards students with the privilege of not having to work. Segmentation has less to do with time, and more to do with the topic or activity in question. This means that there is a back and forth between topics and the one that appears most appropriate in a particular situation is the "chosen" topic.

I look at my entire graduate school experience as segmentation, trying to pinpoint which aspects of communication I wanted to study and coming to terms with the fact that I could not possibly explore all of my interests. I had to make a choice; that choice is what led me to my decision to explore FGC students. Balance is about compromising. 
All of the polarities in this pattern are equal. Balance is something that I look to regularly when I experience tensions: finding balance between work and school, finding balance to make time for my partner, family and friends, and finding a balance between taking enough time for myself and minimizing feelings of guilt for being selfish. Integration, on the other hand, looks at each separate polarity, and fuses them together. Integration is what I found during my second year of graduate school. Integration is my answer to tensions when I cannot seem to create a balance. I find ways to take separate polarities and bring them together (e.g., the art of multitasking). Recalibration, or a resetting, means that the tensions are placed into a different context so that the tension is no longer perceived as a tension, essentially changing the meaning.

Recalibration is what I turn to when I get to the point where I need to adapt a different lens to view tensions. Frequently I work so hard to find an answer to tensions, that I need to take a step back, reset, and revisit what I am working on for new ways of exploring it. The eighth strategy is reaffirmation, the opposite of disorientation, viewing tension and views positively. It was not until recently that I have been able to actually view tensions positively. For much of my time in graduate school I chose to resist tensions altogether and only deal with them when I could no longer ignore them. Through doing this research, and reading about these strategies in relation to my own experiences in dealing with tension, I see how through use of these strategies, relational dialectics offers a new voice to the ongoing conversation in communication studies on the beginning, middle, and end of relationships (Baxter \& Montgomery, p. 73). These strategies allow my research to explore multiple identities offering suggestions to FGC's 
for how, through multiple lenses, students/teachers can learn ways to manage tensions in the classroom and beyond.

I am interested in how FGC students engage, or do not engage, in dialogue as a result of liminal tensions students may be experiencing. To fully engage in dialogue, participants must fuse their perspectives to some extent while sustaining the uniqueness of their individual perspectives (Baxter, 2004, p.181). Relational dialogue is often viewed as being between individuals. Researchers have begun applying the dialectical approach to the study of groups (Prentice \& Kramer, 2006). This will serve as particularly helpful for me as I intend to apply this approach to the FGC student population. Prentice and Kramer (2006) note that some of the same strategies used for managing tensions in groups are comparable to studies in the field of communication studies, which include research on interpersonal relationships. Though researchers have explored relational dialectics in many areas, my interest is primarily located in classroom settings. I have yet to find a large body of research that looks at relational dialectic theory in relation to classroom dynamics (i.e., Hennings, 2009; Prentice and Kramer, 2006). Even less research exists on how first generation college students negotiate tensions in a college classroom.

Hennings (2009) adopts Prentice and Kramer's (2006) definition of dialectical tension in a college classroom as way to explore what types of strategies graduate teaching associates (GTAs) use to manage dialectical tensions. I find this body of research useful in providing a framework for my exploration into how FGC students manage dialectical tensions in a college classroom. For that reason, I will use Prentice 
and Kramer's methods as a way to enter an ongoing body of work, which looks at dialogue in the classroom.

Prentice and Kramer (2006) identify three tensions in their study: (a) Whether or not students choose to participate or stay silent during class discussions (i.e., whether a student is silent or vocal in a college classroom has more to do with learned experiences and needs of students than a student's ability to succeed in a classroom); (b) students' interest in how class activities are conducted in regards to the predictability of activities (i.e., the frequency and similarity of class activities), and (c) how students create time for their personal lives and their school lives (i.e., balance school and work, or school and responsibilities at home). Through identifying these tensions, the authors push for a greater understanding of student behavior in the classroom, arguing that both students and teachers need to develop a more inclusive view of the elements that combine to create these tensions. Quite often in both undergraduate and graduate courses, a student's reason for participating in classroom dialogue varies. The reasons for attending class and participating in class can have nothing or everything to do with the teacher, yet a teacher may perceive that the student is not taking college seriously. Prentice and Kramer's research illuminates that students may base their value on in class participation around the reactions or behaviors of other students, illustrating how a student's involvement in class can have more to do with the students in the class, and less to do with the teacher (Hennings, 2009). Students' choices for becoming involved in classroom dialogue are often due to epistemological views towards safety in classrooms; if a student feels the classroom is a "safe" space, they may be more likely to take risks in the classroom or 
expose their opinions because their espoused belief of a safe space is one where their opinions are not threatened or questioned by the teacher or students'.

Prentice and Kramer's (2006) application of Baxter and Montgomery's (1996) theory illustrates the complexities of relationships, specifically those within a classroom setting. We can see how personal experiences can be a roadblock towards creating meaningful dialogue. Education often becomes personal; we see this when one student gets in the way of another student's access to knowledge. I frequently see this in graduate seminars in which some students want to engage in a discussion that leads to areas of discomfort for other students (e.g., whiteness, race, gender, sex, social class). If students and teachers can gain a better understanding about how these tensions develop, then perhaps tensions can be more clearly addressed by inviting students who would have otherwise remained silent a chance to speak and inviting those students who do most of the talking an opportunity to listen; only then can true dialogue develop.

I am interested in gaining a better understanding for how FGC student status could be contributing to this dialogic exchange (or lack thereof). I have yet to find a communication scholar who looks at FGC student experiences from the perspective of relational dialectics theory. Like Hennings (2009), I see a utility for this theory and its ability to unpack the complexities of a college classroom. I see this theory as a useful lens from which to view the FGC student experience (p.10). Although I will be looking at FGC students as a group, I will also be looking at how they, as individuals, negotiate tensions. As a group, FGCs may experience different sets of tensions. My research will focus on the differences that create this group; race, sex, gender, social class standing, 
and (dis)abilities, illuminating how these identities play a role in how students approach relationships in a different ways.

There is a tendency to carry our outside experiences with us into the classroom. In fact I am not even certain it can be avoided. As a result, tensions develop regardless of how "safe" the space can seem. Therefore, relational dialectic theory presents itself as worthwhile, allowing a way in which we can recognize and understand these liminal tensions of contradiction (Baxter \& Babbie, 1996; Cornforth, 1968; cited in Hennings, 2009, p. 10). "The 'self' in singular form, is a misnomer; it does not capture the multiplicity of the process [ I ] have been describing. One's identity is awash in the tides of different relationships, each one providing a crosscurrent version of who a person is, or more accurately, is becoming" (Baxter \& Montgomery, 1996, p. 159). Let us assume, for the nature of this study, that relational dialectics theory sends us in the direction of believing in multiple selves, each self evolving within the context of our relationship with another (Baxter \& Montgomery, 2006). By acknowledging this, we are then placing emphasis on the dialectical existence of social beings, bringing attention to the contradictions that thrive within these different selves (Baxter \& Montgomery, p. 159). The authors take a both/and approach to creating effective dialogue, insinuating that either/or is not inclusive dialogue. I intend to approach my research from the same lens. When analyzing multiple identities, it is appropriate to also speak to the both/and-ness of an individual. I, like Hennings (2009), turn to Baxter and Montgomery (1996) for a framework on how to locate strategies that FGC students can use to manage dialectical tensions of identity management. 
Limited research exists concerning the needs and characteristics of FGC students and how these factors affect their communicative process in classrooms. Putman and Thompson (2006) note that existing research provides generalizations about FGC student experiences, often from the perspective of white, middle to upper class students. What current research does not do is call out aspects such as race, gender, age, abilities, and socioeconomic status (Orbe, 2004). These findings illuminate the necessity for my research to build on what we already know, proposing a broadening framework to include the unknown. Additional research on FGC students of all colors, abilities, genders, sexual orientations, and social class standings must have a greater representation in the field of communication studies. As a first generation college student, I am growing increasingly aware of the cultural and societal differences that exist among my graduate program cohort. In the same way that this makes us a diverse group of students, it has also become a dividing factor at times. Several in-class conversations pertaining to culture have led to heated debates about whiteness and minority groups; some students find that they simply cannot relate to others because of perceived social or cultural differences. It is here where my interest in identity theory (in the classroom) began. Week after week, students share space in a classroom and merge differences in hopes to develop theory, create and co-create new knowledge. However, a student's cultural patterns generate ideologies, which can make discourse within classrooms feel more like a negotiation. Some students tread lightly so as not to offend others when they speak, some take a very aggressive approach to stimulate worthwhile discussion, and some students sit back in silence, feeling as though they are misunderstood. 


\section{First Generation College Students and University Surveys}

As more and more first generation college students enter universities, the need for understanding how these students matriculate through the university is growing. Not only is there a lack of extant research on FGC students, but much of the research looks at identity of FGC students in terms of success rates and how likely a student is to drop out of school. These negative characteristics, however, should not define FGC students and there is a great need for minimizing these types of reports (Davis, 2010). Reports of this nature generate surveys, which often include close-ended questions, making students choose between either/or, ultimately eliminating the option of both/and-ness. Survey questions of this type typically equate gender, race, and social class with success rates. These kind of data is both incomplete and detrimental to the FGC student population. Davis (2010) asserts that counting FGC students is difficult but essential. Davis argues that, by counting this population of students, the university can become more aware about the rate at which FGCs are enrolling in universities. However, Davis's research insinuates that, with this information, universities will offer assistance to FGC students to ensure their success. Davis goes into specific strategies universities can use to count students, including modifying undergraduate admission applications to include an area where students can enter the level of education their parents or guardians have. Another strategy is to survey students in courses that all students must take in their first year (e.g., freshman composition). With this strategy, Davis hopes that it would provide a platform for institutions to educate students on FGC students' status.

Counting students is part of the process of understanding how many FGC students are attending college. Yet, there is still much we do not know about these students, aside 
from the statistical data on their presence on college campuses across the United States. Orbe and Groscurth (2004) analyze first generation college students' communication strategies both on college campuses and at home. They begin a conversation towards looking at sources outside of the classroom that may be contributing to why particular FGC students may or may not be successful in a university. FGC students are often labeled "at risk" or remedial before they even step foot in a classroom (Fassett \& Warren, 2005). Orbe and Groscurth (2004) argue that although some of these students may struggle in school, it likely has less to do with their ability to perform in the classroom and more to do with a lack of support within their family or home life. As a result, the authors propose further research into the experiences of FGC students through the lens of co-cultural communication.

In its most basic form, co-cultural communication allows an understanding into the process by which members of underrepresented and groups enact certain communication practices when they are in social situations where they feel oppressed (Orbe, 1998; cited in Orbe and Groscurth, 2004). Over the course of several years, the researchers conducting this study communicated with FGC students in both focus group and in-depth interviews as a way to determine how these students communicate self. Orbe and Groscurth are forthcoming in stating that diversity was a large factor in how students determined their identity towards one co-cultural communication pattern, because the diverse population likely contributed to students feeling more represented than students who were not exposed to a diverse population. While this was an effective framework for their study, it did not go far enough in looking at how FGC students 
manage their communicative experiences in the classroom, should they not classify themselves under the guise of a co-cultural identity.

\section{First Generation College Students, Identity, and Liminality}

People co-create different selves with their parents, friends, partners, co-workers, children, and those close to them (Baxter \& Montgomery, 1996, p. 159). These selves come together to form a self, each weaving into the other, creating different dialogic experiences. For first-generation college students, these selves combine with students' relationships with faculty and their peers. These selves play a large role in the creation of multiple identities, some of which they do not give themselves, but are other identities bestowed upon FGC students before they even set foot in a university. I turn to Fassett and Warren (2005) for their research on educational identities of students who are labeled "at risk" because FCG research is largely focused on attrition rates of these students. Understanding the educational identity of students is paramount in gaining a better understanding of how labeling students can be detrimental to their ability to succeed.

Fassett and Warren provide three rhetorical strategies for looking further into the problematic assumptions about education: appeals to individualism, appeals to authenticity, and appeals to victimization. Individualism speaks to the ways in which individuals locate success or failure of others and of themselves based on individual actions. Fassett and Warren find this rhetoric problematic because it leaves unquestioned meritocracy within the educational system, implying that anyone can earn the richest rewards, regardless of social circumstances. Authenticity as strategic rhetoric refers to truth or reality that exists outside human actors, meaning a pursuit for distinguishing the true from the false. This proves problematic because a comparison model develops, 
where one is always compared to another. The third rhetorical strategy is victimization, normalizing the role of communication in education and other social systems. This insinuates that when rhetoric of victimization moves through individuals within the social system are viewed as weak or passive by others (pp. 247-249). Fassett and Warren bring to light a visualization of how discourse such as "low income," "underprivileged" and "at risk" create limited visions of hope (p. 244). These identity markers are often masked, and make it difficult for researchers to broaden their understandings of first generation students, or any students for that matter.

Fassett and Warren ask their readers to recognize that research constructs educational identities in ways that do not easily allow for growth because students' identities are measured and counted as a means to solve a problem, instead of studied and explored as a means to understand the particular needs of these students; as a result, they are left to fail (Fassett and Warren, 2005, p. 253). Similarly, researchers typically count and measure FGC students as a means to bring funding to the educational institutions they attend. Although these students are counted, few schools are acknowledging the need to understand what types of support these students need to succeed, thus creating statistical data showing retention rates based on success or failure without looking at the identities of these students or listening to the ways that allowed them to succeed or fail in higher education. I wonder if the very educational institutions they are attending are failing them, by not listening to their needs and utilizing their bodies as a way to generate financial support for the school without providing the appropriate social support for the students. 
The focus on retention rates has its place in academia, however without looking at the support provided to students, it is difficult to gain a full understanding behind a student's level of success. In my exploration of first generation college students, I look to Rosenfeld and Richman's (1999) account of social support in classrooms, detailing how different forms of social support associate with different outcomes for students' success rates. Orbe's (2004) narrative of first generation college students reveals insight into my study by showing identity negotiations in communication between first generation and second-generation college students attending graduate school. Lancaster (2010) builds a foundation for looking at this from an intersectional approach by highlighting some of the inequities that society places on academia and the barriers that exist for first generation students who are less familiar with the rigor of coursework that is associated with higher education. McLaren (1993) further contributes to my study, showing that rituals facilitate performative constitution of identity such that rituals create privileged categories. McLaren argues that classrooms do not manifest as disembodied entities; rather, classroom culture produces competition and conflict of disjunction between social class, culture, and symbolic conditions. Though this body of literature illuminates FGC graduate students and second generation graduate students, aspect of this research allow me to adapt an alternate approach: evolving current dialogue on first generation college students to reflect experiences on a greater level.

As a FGC student, I intend to adopt a critical lens to understand how students are successful in higher education, despite any specific social inequities they may face. Social support is a communicative process, which closely relates to realities of FGC students. Rosenfeld et al. (1998) provide a definition of social support that proves helpful 
in defining how we communicate the need for support. The researchers define social support as a communication process that increases the amount of personal control a recipient feels. Support of this nature lessens uncertainty, difficulty or randomness that may occur through areas such as: seeking advice, emotional assistance, financial aid, and guidance with writing. First generation college students seek out social support in a myriad of ways, and I am interested in understanding how these students seek support and from whom they receive it. Research shows that most FGC students are not able to seek social support from home; their parents do not understand their workload and pressure. There is a negotiation that takes place for many first-generation students, where they seek out other first generation students in their programs, resulting in a community of students relying one another for social (e.g., academic and emotional) support. This creates a network among students that mimics what first-generation students may not be getting from their families.

First generation college students often create relationships within their cohorts, which act as systems of social support within the culture of higher education (McLaren, 1993). Current authors, such as Orbe (2004) and Davis (2010), researching firstgeneration college students develop discourse surrounding the effects that the level of school involvement has on the students, but they rarely discuss how we can help firstgeneration college students who are actively seeking support or facing inequities. I raise the question: how do you perform rituals of college if you have not experienced them? Studying the intersections of gender, race, sex, and social class illuminates deficiencies in current research. I discuss each in terms of one or the other in relation to FGC students, but research is lacking in terms of multiple inequities. "As a nation, we are afraid to have 
a dialogue about class, even though the ever widening gap between the rich and the poor has already set the stage for ongoing and sustained class warfare" (hooks, 2000, p. 1). By recognizing social class and other social inequities in relation to social support of firstgeneration students in higher education, researchers can gain a more complete understanding of the rigor that takes place in completing a degree in communication studies, whether undergraduate or graduate. Current research on the experiences of first generation college students focuses extensively on the drop out rate of those obtaining their bachelor degrees (Orbe, 2004). I am interested in understanding the reason behind attrition rates of FGC students along with the success rates of these students. However, I cannot approach a new way of researching this phenomenon without including an examination of FGC students' identities (e.g., race, gender, sex, ability, and class).

\section{Research Questions}

The goal of my research was to go beyond presenting strategies to universities for how to count the FGC student population. I also intended to refrain from sectioning these students off into a culture of their own and study success or drop out rates without looking at students as complete selves. Alternatively, I will used dialectical theory to show how communicative tensions play a role in how institutions of higher education form identities for FGC students, and how FGC students identify themselves, both inside and outside of the classroom. The following questions were the focus of my study:

RQ1: How do first generation college students communicate dialectical tensions in the classroom?

RQ2: How does a first generation college student's access to navigating college contribute to success in higher education? 
I, like many other FGC students, have a story to tell. I cannot separate myself from my work in the classroom. Embodying this identity provides a framework for my studies. Focus group interview data were helpful to this study as a means for me to hear the experiences of other FGC students, but also so that participants could share their experiences with each other. In this way, the focus group interviews served a pedagogical function, helping students support each other and giving rise to possible classroom actions. Dialogue can also be a critical component in the development of knowledge at all levels of higher education because dialogue encourages a useful exchange of ideas, promotes support inside and outside of the classroom, and provides a platform for students to voice their experiences (Simpson, 2003, p. 117). 


\section{Chapter Three: Methodology}

I feel like a number. Every time I fill out a survey, I struggle because I do not fit into any of the prescribed "boxes" that are placed "conveniently" on the page, as though it is supposed to do me some sort of favor to tell me what categories I fall under. But my identities (i.e., race, gender, social class standing, ability and age) are much more complex than just finding the check box that "best describes me." I struggle with how meaningful this information really is. These types of data collections are not inclusive of all identities and therefore only gain information about aspects of a student's identity. The box that I have become most accustomed to checking is the "other" box. I become even more uncomfortable about these types of surveys when they ask for information about my parents' background, specifically their educational background. How do I report that my mother and stepfather have a college education but that they earned it after I attended college, and at what point is there space to disclose that my father does not have a traditional college education (i.e., a degree from a four year university)? I see terms like "some college" and wonder how that is helpful, if at all. My father is a skilled sheet metal worker and holds the equivalent of a degree from trade school; yet, surveys do not include this type of information because he does not have a degree from a traditional college, therefore the checkbox "some college" is exclusionary in this instance, eluding that my father is uneducated in the traditional sense, when in fact he did complete a professional training and is well versed in a particular subject, much like that of a college graduate. This makes it very difficult for me to break down how it is that I come to identify myself as an FGC student, and, depending on how I fill out the survey, I may or may not be counted as one. 
My interest in completing this analysis is to illuminate current research on firstgeneration college students and social support by shifting research to include identity management in conjunction with an intersectional analysis. An intersectional approach to research asks important questions and builds a foundation for understanding how multiple systems of oppression work simultaneously to create identity. Intersectionalities include, but are not limited to, race, age, gender, culture, ability, sexual orientation, and socioeconomic standing and examine historical, social, and political contexts. I am a first-generation college student, however that is not my only identity. When looking at social support and first-generation students we need to have a more inclusive view so that we can engage in holistic research, recognizing multiple oppressions occurring simultaneously. Intersectional analysis allows a critical lens through which to view social support and the communicative process among first generation college students. This will allow a re-framing of how scholars conduct research around this. By utilizing an intersectional approach, the questions we ask will change and the results from our studies will include a greater representation of all identities. Multiple identities combine to provide spaces for empowerment and for dis-empowerment. This perspective is useful because it gazes at patriarchy and discrimination as they create inequality within academia, irrespective of one's identity as a first-generation student.

\section{Autoethnography}

"Why do you keep using 'I' when you write? Why are you involving yourself in this research? It makes your work sound un-scholarly. I think what you should do is take out any reference to yourself and make this work objective. The readers might not want to know about your experience." I was in a writing class where several peers proofread 
each other's work. Having come from an FGC student background, I was already

anxious about having my peers read my work because I did not feel like I was as good a writer as others in my graduate cohort. I was self-conscious about my work; this only added to my feelings of tension and anxiety in this writing class. So, I did what my peer suggested, I did my best to eliminate myself from my work, and speak in general terms, but by doing that, I changed the tone of my paper, ultimately undermining my efforts to create agency in my writing. The passage below describes ways in which scholarly writing can include the voice of the author and still remain a credible contribution to the field of communication studies.

Scholarly writing is largely self-less. It is writing that avoids references to self, or doubt, or procedural ambiguities, or personal vulnerabilities. As well, it is writing that makes no references to the quality of lived experiences as a person, an academic, or a field researcher. It is writing that, looked at one way, is ungendered, divorced from classconsciousness, and is unable or unwilling to give voice to its own racial or sexual subjectivity. Yet viewed another way, to date it has been writing that privileges masculine, middle-class, heterosexual and white rhetorical and critical standards; it is writing that above all has displayed the values of academic culture and institutional life. (Goodall, 2000, pp. 190-191).

By writing in a way that is largely self-less, I would be writing in a way that continues to privilege those who have access to and understanding of academic culture. Alternatively, by writing in a way that is scholarly, but also accessible, I can write to both those who are familiar with academic culture, and those who may not be. As I began writing portions of my thesis, I often questioned including my personal experience as an FGC student; I did not want it to distract from other students' experiences, and I heard constant echoes of my peer's voice telling me that my professor and/or my classmates might label my work unscholarly. However, by writing in my voice, I can create writing that is both scholarly and accessible. Goodall refers to self-reflexive writing as a new ethnography, meaning 
that this type of ethnographic work blossoms out of the personal experiences of the person conducting the study.

New ethnography, ideally, does not behave in any of these ways. It is writing that is unnamed, and in some rhetorical ways, undisciplined. It overtly privileges the personal over the so-called objective, and if its good, it dissolves any idea of distance, doesn't present "findings," isn't generalizable, [and] only has credibility when self-reflexive, and authority when richly vulnerable (Goodall, 2000, p. 191).

Essentially new ethnographies are narratives, directed towards academic and public audiences, and are rich in personal experience within a culture (Goodall, 2000, p. 9). Goodall asserts that new ethnographers have an obligation to write about their lives because in order to create work that is new ethnography one must ensure his/her observations and evaluations of others are portrayed in a credible, self-reflexive "voice" (p. 23). I look to Goodall (2000) and Fassett and Warren (2007) for an in depth explanation of the "why" behind my choice to incorporate autoethnography into this body of work. In order to uncover how cultural patterns of oppression enter the classroom, I will use myself as a prism for a representation of multiple identities. I identify not only as a woman, but also as a heterosexual, lower middle class, first generation college student. Each identity intersects, forming multiple identities.

As I near the completion in my MA program, it is becoming clear that I would not even be able to write this thesis if it were not for my direct experience identifying as an FGC. I will offer my experience as a platform for understanding where other students' stories manifest. We all have our own individual experiences, but we share a commonality, and I would be remiss in denying my voice in this piece. As a writer, "I must be present in the document in order to identify from where I, as a critic, speak" (Fassett \& Warren, 2007, p. 98; authors' emphasis). It is important that I hear the 
experiences of other FGC students; their stories are no less critical to this study than my own. I want to acknowledge what makes "good" narrative passages and how I will ensure that I am not focusing on the inward self as a way to uncover my experiences, but rather how I will use my experiences as a way to offer guidance to my readers and ultimately strive to create change through advocating social justice (Goodall, 2000). While my voice weaves throughout my study, it is important that my readers not only hear my perspective on being an FGC student. Rather, by sharing my narratives, I hope to invite a dialogic space for other FGC voices. Human activity consists of action and reflection; it is praxis, and as such, requires theory to illuminate it (Freire, 1970, p. 125). I am still in process, as a person, as a student, as a woman. I am not sharing my experiences to show that I have mastered how to be a successful FGC student; rather I intend to show that I still grapple with identity management, and I am also interested in how others in the FGC student community communicate their experiences in the classroom.

\section{Reflexivity}

According to Freire (1970), praxis requires both reflection and action. I, like other FGC students, hold many identities that intersect with one another. So, to separate myself from this work goes against my intention of showing how, through narrative of my own experiences, I can better understand the experiences of others. Leaving my narratives out of this work would not allow me to reflect or create a call to action. Though my intent is to expose systems of oppression and reflect on my experiences as a way to create change, I do not only want my readers to feel or experience my reality as an FGC student; rather I want to share the experiences and realities of this student body. I 
wish to work together to expose systems of oppression and work with this student body to enact change. By working with FGC students I can illuminate the multiple identities within these students as a way to show institutions of higher education that FGC students are more than just numbers, and more than just check boxes on a survey. My hope is that, by sharing my experiences, I can open the door for other FGC students to share theirs.

I did not always recognize the privilege in my life. It was not until I was accepted to graduate school that I realized how privileged I am. I later learned that not having to recognize this is a privilege in itself. I spent a great deal of time "coming to class consciousness" (hooks, 2000, p. 24) by being reflexive about my own life. I learned the importance of acknowledging my place in this world and how I got here. This helped me to learn that reflexivity is less about noticing privilege in others, and more about recognizing it in within ourselves. Once we can recognize privilege within ourselves we can gain a more clear understanding for how it plays a role in our lives and shapes our experiences, as well as the experiences of others.

Before I can analyze the experiences of others, I must first hear my own voice and gain clarity on my own identity as a FGC student. Fassett and Warren (2007) detail writing as a process of meaning making; this process goes beyond being helpful for the reader, it is also a useful tool for the writer (p. 105). I believe that I would be remiss in not including myself in this study. Hennings (2009) states that autoethnography provided her with a way to explore and illuminate the tensions that are inherent in others' experiences, creating a deeper awareness; this awareness contributed to the overall understanding of the tensions that shaped her individual experiences (p. 34). I intend to 
utilize autoethnography in the same way. I want to uncover the tensions in others as a way to further my knowledge in how these tensions may also play a role in my experiences. Madison (2005) asserts that self reflexivity through autoethnography is vital because it "forces us to acknowledge our own power, privilege, and biases just as we are exposing the very power structures that surround the community or subjects that we study" (p. 7).

Being a FGC student is part of who I have become. I recall countless times when, while seated in a classroom, I felt hurt. These feelings of hurt and inadequacy play a large role in my culminating experience and are the guiding force behind this study. I have not hurt in every class all the time, but I have left classes wondering if I have what it takes to succeed in graduate school. "In order to have a changed world, in the context of an educational system, we must hurt students less" (Fassett \& Warren, 2007, p.192). One way this can be done is by offering alternative approaches to scholarly writing. "Autoethnographic writing invites us to breathe in deeply, to take up and take in someone else's experiences" (Fassett \& Warren, 2007, p. 22). Writing is a form of inquiry, and as such, it is vital to allow readers to see the processes that I bring into what I am interpreting, even if the interpretations do not offer a direct solution (Goodall, 2000, p. 9). I struggled with locating ways to negotiate tensions of being an FGC student, wanting so badly to succeed, and feeling oppressed in the classroom. "As we recognize the vital importance of illuminating the researcher's positionality, we also understand that critical ethnography requires a deep and abiding dialogue with Other as never before" (Madison, 2005, p. 8). Critical ethnography is ethnography with a political purpose, "it begins with an ethical (i.e., compassion for the suffering of human being) responsibility to address 
processes of unfairness or injustice within a particular lived domain" (Madison, 2005, p.

5). While critical ethnography calls for political agency, Madison asserts that politics alone are not enough. Ethnographic researchers must include self reflection in their work. They must create dialogue with self and other in order to fully achieve a critical ethnography.

\section{Participants}

For this study, I conducted 4 focus group interviews with a total of 16 FGC students. All participants are FGC students currently pursing an undergraduate degree or masters degree and are enrolled in courses in the Department of Communication Studies at San José State University. Stewart, Shamdasani, and Rook (2007) assert that contemporary focus group interviews generally involve 8-12 individuals; they go on to state that experience has shown that smaller groups may be dominated by one or two members and larger groups may be difficult to manage because involvement from all participants may be inhibited due to the large number of individuals (p. 37). I chose to conduct 4 focus group interviews because wanted to ensure I would gather a variety of interviewees so that I could hear many individual perspectives. No one FGC student experience is the same as another.

When engaging in dialogue, people are at once actors and objects of their own actions; dialectical theorists refer to this as "praxis" (Baxter \& Montgomery, 1996, p 13). However, this praxis is different from Freire's in that Baxter and Montgomery situate praxis in varying aspects of social life, depending on their interests (p. 14). Although Freire articulates praxis from a point of reflection and action in a way that transforms the world, Baxter and Montgomery approach praxis from a dialogical standpoint. This 
concept of praxis refers to subject and object within the nature of human experience.

This means that our actions are informed in part because of what takes place during the course of a relationship, and this often stems from one's own self interest.

Dialogue is both difference and unity, both agreement and disagreement, both a separation and a coming together (Madison, 2005, p. 9). It is my hope that, by creating a dialogue between the experiences of others and the experiences of self, I established intentionality within the focus group interviews I conducted because of my understanding of what types of questions I could or should be asking. Though I did not want my personal experience to dictate what questions I asked, the dialogue provided a foundation for how to develop meaningful questions, irrespective of whether they directly related to my experiences. Though I embodied my research, using member validation also helped ensure that I would not look at this research solely from my own standpoint. After all, we are not simply subjects, but we are subjects in dialogue with the other (Goodall, 2000, p. 9).

Member validation is a crucial component to focus group interview data because it requires the interviewer and the interviewees to share power (Lindlof \& Taylor, 2002). My interest in approaching the data autoethnographically and intersectionally did not lie in trying to produce fluidity throughout the study but rather the opposite: "I want to contemplate self, while in relation to the others that I am studying" (Fassett \& Warren, 2007, p. 168). In doing so, I worked to be cautious so as to not lead my interviewees into particular answers that they thought I might want to hear.

Focus group interviewing develops a view of something between (inter) people (Brenner, 1985 in Lindlof \& Taylor, 2002, p. 170). By conducting focus group 
interviews, I could include the perspective of other FGC students into my research. This allowed a more detailed look into the lives of these students, and offered multiple standpoints on how each student negotiates the tensions of multiple identities in the classroom. The overall goal of my research is in line with qualitative research. My intention is to isolate and define categories during the process of research, rather than do this prior to conducting research (McCracken, 1988, p. 16). I used an inductive approach to analyze these interviews. Inductive analysis is an intimate way of engaging in research. Kvale (2007) states that qualitative research refrains from setting up a welldefined concept of what the researcher intends to study. This body of research also avoids formulating hypothesis at the forefront of the study; instead hypotheses develop while the research is taking place (p. 6). Doing this prior to conducting research risks undermining the voices of the interviewees.

\section{Interview Procedure and Protocol}

I conducted the focus group interviews between March 21, 2012 and April 2, 2012. Each focus group interview lasted between 90 and 120 minutes and was audio recorded, and transcribed. I obtained IRB approval for all interviews. At the start of each interview, I obtained informed consent from each participant, and I also asked each of the participants to choose a pseudonym. My interview protocol was based on two research questions; I grouped my interview questions in such a way that each one would be associated with a particular research question, as recommended by Kvale (2007). This ensured that each interview question adequately addressed my research questions. 
Although there would be similarities, I did not expect any one story to mirror another. For my selection pool, I was interested in interviewing both undergraduate and graduate students so that my research would explore the experiences of both. I believed that both student populations experience and negotiate tensions in different ways, and my research would benefit from including voices of a "college" experience, rather than a "graduate or undergraduate" experience. According to Flick (2007), when you orient yourself into your study, you develop more knowledge about the field and the people in it. I developed open-ended questions so that I could invite a space for the interviewees to express their experiences through their voices, identities, and realities. A smaller group of interviewees would not be as representative as a study that draws upon a larger amount of participants; therefore, I do not want to imply that this student population will be exhaustive or be the voice of all FGC students, but I was interested in entering an ongoing conversation on FGC student research. Developing focus group interviews with 4 separate groups of FGC students allowed me to hear more of the students' stories, apart from just answering my questions. My hope is that we shared power in the space where the interviews took place and allowed sufficient time for meaningful dialogue to take place. Because ethical issues are associated with interview research, it was important that I established a balance between my interest for wanting to know more about this area of research and developing a space for the interviewee to feel free to share his/her experiences (Kvale, 2007).

\section{Data Analysis}

Prentice and Kramer (2006) guide my analysis. After transcribing and analyzing each interview, I made extensive notes on concepts, stories, and experiences that stood 
out to me, and, as themes emerged, I created categories so that I could keep track of issues that participants shared across the interviews. After completing the categories, I followed the structure that Prentice and Kramer recommended, and I reviewed each category to identify the tensions that emerged from the stories that the FGCs shared. I worked inductively, as this style invites analysis that is consistent with the tone of my research and provides a platform for the FGC students' voices to provide insight and meaning behind the tensions that emerged. By not creating categories ahead of time, the voices of the FGCs, along with my own voice, created space for stories to illuminate experiences organically.

Weaving my voice throughout my study helps the reader to understand my experiences, but I do not want my experiences to speak for others. By including others and self, I can be observant of what others are saying and track patterns that may develop across all participant experiences. My voice, though subtle, is all that I have; at least I feel that way at times, and I imagine there will be times during this process that I feel this way. My voice triggers dialogue with others and creates meaning. It is through this dialogue that I begin to make sense of my realities as a FGC student and while this study does not answer all of my questions and it may not silence all of my fears, my hope is that it will spark a voice in someone else. I hope that by using my voice and by illuminating the experiences of others, the meaning that is created through these interviews will encourage social action so that the voice of others and myself can become the voice of many.

In the following chapters, I discuss FGC students' responses to the interview questions and indicate the implications of what participants shared in the focus groups. 
First, I will identify the dialectical tensions that emerged from the narratives participants shared in the focus group interviews, then I will unpack these tensions and speak to the impact these tensions have on FGC students, paying particular attention to the different ways in which FGC students manage these tensions. My goal in the chapters that follow is to bring attention to the experiences of the FGC student experience in a way that honors their stories and perhaps brings a greater appreciation and understanding for the types of challenges these students face. 


\section{Chapter Four: Findings}

As a first generation college student, I often wonder if there are other first generation college students who experience similar highs and lows. I came to this research as a way to try to make sense of my experiences in the classroom and my experiences in trying to navigate university systems. I often experience feelings of inadequacy, wondering if my writing is good enough, if I am grasping the reading for the class, and if my participation in class is meaningful. Even as I embark on my last semester of graduate school, I still have moments where I experience self-doubt. While conducting focus group interviews, I felt a sense of relief, enlightenment, and sadness. I experienced moments in the interviews where I could not avoid wanting to acknowledge and validate what others were sharing because they were struggles that I had directly experienced. And, although I could see similarities in some stories, there were others that I could not relate to; those were the stories that allowed me to really be in the moment, to be "in" the interview, and reflect on how different the experience of being a first generation college student can be for others. However I was also pleased with the amount of new information I learned. I was humbled by how forthcoming the participants were, and I learned a great deal about how a community of students can share so many commonalities and yet also experience completely different journeys as first generation college students.

One of the best lessons I learned from conducting this research was finding that first generation college students have similar experiences in the classroom, in navigating the university, in their lives at work and at home, in social interactions, and the in the ways in which they intersect. We each had our own reasons for pursuing college, our 
own inspiring story that pushes us to continue on during those moments when we just want to quit. We also experience feelings of pride and uncertainty in our own ways, and we have experienced disappointing moments in classrooms or with university administration, which can be so difficult to navigate that it seems almost impossible to succeed. But, regardless of all of this, we continue on in the pursuit of higher education. We made it this far; we got in, and we are here for a reason: to see our dreams blossom into reality. First generation college students are completing an educational journey that no one else in their family has yet had the privilege to complete. As such, each day is welcomed with a sense of pride and a strong sense of desire to overcome all of the hurdles that present themselves in higher education. It is important that first generation college students remind themselves that this is where they belong, if this is what they choose.

First generation college students do not all experience the university through the same lens. Although college is a place for exploration and self-development, not all FGC students have equal experiences at the university level, and it is important to respect that while there are similarities, it is unfair to lump all FGC students into one category. Several themes emerged through these participants' dialogues: the desire to create balance in life and learn to accept instability, the desire for social support while also learning to rely on oneself, and the experience of feeling privilege by being the first in their family to attend college while also feeling oppressed by experiencing the effects of social class and silence in the classroom. Although these themes carry overarching similarities, they are not intended to encapsulate everything that a first generation college student experiences. These are themes that emerged during the focus groups that I 
conducted, and they speak to the ways in which FGC students manage multiple dialectical tensions. These findings help to answer this study's two research questions. RQ1: How do first generation college students communicate dialectical tensions in the classroom? RQ2: How does a first generation college student's access to navigating college contribute to success in higher education? In this chapter, I will provide a detailed response for each of these questions and offer strategies used to negotiate and manage three common tensions the students reported experiencing between their lives, the classroom, and the university. These three tensions are: Instability and stability, self support and social support, and disclosure and silence. These tensions are situated within the framework of Baxter's (1990) tensions: predictability and novelty, autonomy and connectedness, and openness and closedness.

\section{Instability}

As a student working full time, I personally experienced the effects of instability as result of the role that social class holds in my life. Like hooks (2000), I have long struggled with how it holds a place in my life and have not come to terms with it (p. 2). I have felt the financial highs and the lows that social class difference can bring. I have experienced what it is like to "go without," so I could pay for classes while waiting for my student loan to come through, and I have experienced the high of being able to work longer hours, and earn more income. Additionally, when school is out, I am able to spend less on school-related expenses; with each semester, I feel the financial low. This all contributes to feelings of instability. My social class standing has a direct effect on my communication tendencies as a FGC student. Wednesday describes what it is like when social class becomes a part of who we are as students: 
The administrative part of school is difficult, and there is so much paperwork, and the school has been known to lose it. I feel like it is just a step, a roadblock to put in my way and I don't get that. I have a family member who contacted be about a bill they could not pay, but I could not help pay it because I am here in school, but if I was not here, then I could help her. It is poverty issue that I can't fix until I am out of here, and I don't want any more roadblocks. I just want a clean shot.

Social class plays a role in our everyday lives; it is a large part of our realities, and it makes the difference in the types of access provided to students. The policies and practices governing public education are problematic and create an obstruction toward academic achievement, privileging higher education and making it accessible only to those belonging to middle to high social class standing, taking away the freedom of equal access to education. First generation college students are generally most affected by this because they do not always have the same access to higher education that second generation students may have. Once access to academia is gained, the tensions that FGC students are faced with when trying to get into college do not dissolve. These tendencies follow us into the classroom, sit with us, and play a large role in how we engage in dialogue.

Authors Orbe (2004) and Davis (2010) acknowledge that most first generation college students hold full- or part-time jobs as result of socioeconomic standing and, therefore, do not have as much time to dedicate to their schoolwork as second or subsequent generation college students. It is often difficult to juggle both work and school, and if there is not a reference point for how to balance the newness of higher education, in addition to working full time, then students may experience feelings of instability and confusion about where to go to get the support that they need. Orbe's work serves as an important backdrop for current research on FGC students. However, it is 
important to recognize that not all FGC students enter college from nontraditional, disadvantaged backgrounds. Some, as described by Orbe, come from families with considerable "cultural capital" that, in the absence of a college education, still provide significant support for FGC students. In class-based cultures, how one chooses to communicate with another has a great deal to do with reliability, experience, and access. "We are not stones, but continually making our worlds, our relationships, a constant negotiation through how we will choose to respond to another human being communicating" (Nainby \& Pea, 2003, p. 28; authors' emphasis). These factors influence FGC students and non-FGC students in different ways. Davis (2010) argues that first generation status is not the same as low-income status, yet it plays a role in the unfamiliarity an FGC student may feel in a college classroom.

From grade school, students are conditioned to cross the threshold of the classroom believing they are entering a meritocratic space, a free zone where the desire to study and learn makes us all equal (hooks, 1994). For first generation students and second generation students, an academic achievement gap may occur because there is a tendency for first generation college students to spend almost twice as much time working part-time or full-time jobs, as compared to their second generation counterparts (Orbe, 2004). Claire reminds me that the universities "do have a lot of resources, but they don't make them available; you have to go search for them, and you have to navigate and search the website. And, they just don't make the things that we need, like classes we need for our major, easy to find." A large number of first generation students seek employment or educational loans in order to finance their education; as a result, students may experience difficulty balancing the conflicting demands of school and work 
(Brooks-Terry, 1988). This, in combination with a lack of familiarity with the college atmosphere, may leave first generation students less likely to experience the same sense of identity and social integration with the college community that other students experience (Speirs \& Rinker, 2006). These experiences join together to create a tension between feeling instability in the unknown and stability in the known.

With each semester that I am in graduate school, tuition increases, student loans grow larger, and it becomes increasingly clear to me that education is a privilege. The high cost of tuition is creating an epidemic within academia; making it accessible only to students able to afford the high price tag that higher education carries. It took me only a short time to understand that class was more than just a question of money; it shapes values, attitudes, social relations, and biases that inform the way we build knowledge (hooks, 1994). It is also becoming harder to obtain required classes for particular majors due to recent budget cuts at the university. Students often take classes they do not need in order to stay enrolled and remain eligible for financial aid. Theo and Claire describe their personal experiences below:

THEO: My advisors had me minor in art, and right now I am in sculpting classes, and I am an engineering major, but it's very difficult to get classes, and I need the units.

CLAIRE: The units were my biggest problem. I did not understand why they mattered, and I was undeclared, so when I finally declared my major, they told me that I did not have enough units, and so I signed up for a minor, but it seemed like just because you are here two years, you are still a freshman because you don't have enough units to be a sophomore.

Having trouble acquiring necessary units extends a student's time at the university, which results in more financial aid, and, therefore, more debt from student loans, ultimately leading to uncertainty about the future. Each of these components plays a role in how 
successful a FGC student is in college. A students academic standing should not be deduced to a FGC student being a labeled "at risk"; success should be measured on whether or not the institution is providing these students with the necessary tools to succeed.

\section{Stability}

Learning to be gentle with ourselves can be one of the most difficult aspects of being students, let alone first generation college students. During the interviews, students discussed that they needed to find a happy medium between pulling all-nighters and finding time for sleep, and they realized that staying up all night does not always pay off. However, students tell themselves that they will get more accomplished if they stay up all night, therefore compromising their own health and well-being. If students can learn to accept that sometimes we just have to put the paper aside, study at another time, or read the entire book on another day, then maybe there will be less of a struggle with feeling like we cannot establish a common ground with our life responsibilities and with our school work.

For first generation college students, finding stability means learning acceptance of self in relation to expectations placed before us; it involves more than just asking for an extension or taking a day off work to complete a paper. Renee describes the difficulty in gaining stability by learning to strive for balance and what can happen when a lack of sleep prevails:

As a student, I know I could do better, but the lack of sleep and trying to juggle life and finances, everything gets really hard, but being a student, I feel, is an investment into my future. The first four years of my college experience I was under the misconception that grades did not matter that much and I just wanted to pass. I was wrong. As I complete my last year 
in college, I want to prove to myself, my teachers, and my family that I can do this, that I can succeed. Being a student is very lonely; I experience a huge lack of sleep and often stay up nights trying to get papers done. But it's worth it; at least I hope it is.

Orlando provides a summary of the way in which many students learn to gain acceptance and find balance during a time when instability is inevitable:

I think I have the potential to be a better student than I probably am but have to choose a lot of other things, such as work, family, and personal life, and balance everything. Where I could strive for a 4.0, I am more ok with a 3.5 if it means I can have balance in my life and have fun. I am unsure if this is the same for non-first generation students.

Other FGC students shared similar experiences to Renee and Orlando, mostly in relation to learning the hard way that sleep is a necessity, and it does not always pay to rack up a pile of sleepless nights. Many FGCs acknowledged that they have to come to terms with realizing that while they may want an A, an A- is acceptable if it means they can make time for self care.

Although the desire to succeed is strong, FGC students tend to put additional pressure on themselves to succeed, and this is mostly a result of wanting to make their families proud and wanting to prove to themselves and others that they are not "at risk." They are not "different," and they can be just as successful as non-FGC students. Although acceptance is a large part of learning how to negotiate the reality of imbalance, FGC students also struggle with negotiating multiple identities.

One of the defining characteristics of an FGC student is that $\mathrm{s} / \mathrm{he}$ is the first in his/her family to attend college. Like me, other FGC students may not feel comfortable disclosing that identity to others. As a result, students can experience feelings of alienation because they have no one with whom to share their experiences. Students' 
identities shift when they enter college because they become more educated than other members of their family (Orbe, 2004). In some cases, the student can no longer relate to his/her family members, and this permeates her/his presence in the classroom, ultimately playing a large role in how a student comes to identify his/herself. When I asked students how they identified themselves as individuals and as students, many shared qualities that separated who they are as people in the world, outside of a classroom, and who they are as students. Lola, a first generation college student and graduate student described herself as a fun, outgoing person who is secure and confident. But as a student, she described herself as completely insecure, which is the exact opposite of who she is as a person. Lola's identities a student and person support my argument that negotiating multiple identities adds to the struggle of feeling unbalanced in life. Ashley, a first generation college student, stated that she does not really express her creativity in the classroom, but when she is outside of the classroom, she is vocal and states what is on her mind.

Chris echoed Ashley, stating that he is more reserved inside of a classroom than he is outside of a classroom. He asserts that as an FGC college student you don't know what to expect when you walk into a classroom; to that end, he is more reserved and cautious in a classroom than he is in his social life. These multiple identities are tensions within themselves, and when they penetrate into the classrooms it becomes problematic for both teachers and students. Because the student feels that the teacher does not know who $\mathrm{s} / \mathrm{he}$ really is, and might not communicate that $\mathrm{s} / \mathrm{he}$ is struggling with these tensions, the teacher may have difficulty understanding why a student may not be as involved in the class as other students. If we can begin to bridge the gap and come to accept who we 
are, both as people outside of the classroom and as students inside the classroom, FGC students can make room for their multiple selves. With this acceptance, they can begin to gain stability and work to create more meaningful dialogue in the classroom and a larger understanding for failure that does not compromise their desire to succeed. While they want to find balance, they also realize that it won't happen all the time, and acceptance of negotiating multiple identities is key to understanding the stability-instability dialectic.

The Predictability and Novelty Dialectic. The predictability and novelty dialectic is a result of first generation college students feeling conflicted in how to proceed with creating balance in their lives; finding commonality between the stability or predictability of what they once knew and the instability or novelty of new experiences. Many of the FGC students I spoke with hold full-time jobs, or several part-time jobs, in addition to attending college. This creates a challenge for them to balance in their lives and can often feeling like a juggling act between going to class, making time for homework, working at one or multiple jobs, and finding time for a social life. Yet, with everyone I spoke with, no one felt as though they had the option of giving anything up. While attending college is a choice in most cases, the students were not willing to quit, even if it meant they would find more stability in their lives. Deciding not to work is often not an option, as most students rely on their jobs to provide them with the income needed to pay for college. And, while their situation creates feelings of instability at times, it is also what motivates this group of FGC students to succeed.

While feelings of novelty occur, FGC students acknowledge that they yearn for a sense of predictability in their lives. However, the desire for predictability is centered on the people they love rather than within his/her self. Students reported that they feel as 
though they do not do a good job balancing the social aspect of their lives with their education and other commitments, and they often have to compromise friendships, time with their families, and time with their partners in order to gain a sense of stability in their lives. Because of this, they expressed feelings of not wanting to disappoint anyone. Therefore, while they accept that balance may not occur at all times, and are hesitant to give anything up, they also grasp for anything that can create a sense of balance, allowing them to feel as though they can find their center. In this section, I will illuminate these conflicting feelings of predictability and novelty in relation to experiencing tensions of instability and stability, as well as address specific strategies that FGC students use in order to create balance between opposing tensions.

FGC students' strong desire for stability is a result of wanting to have control over a particular aspect of their lives. Often times, when their lives feel unbalanced, FGC students may feel as though they are spiraling out of control. By creating balance and locating a sense of stability in their day to day routine, they establish a feeling that some or all parts of their life are coming together, even if only momentarily.

Chris, a second-year first generation college student, explains what this is like:

I guess the hardest thing is balancing your life at home, at school, and at work. I work long shifts at my job and go home after work and find that I don't want to do homework or write a paper; it is especially difficult when a large chunk of your day is gone from being at work. I get paid at work, but I don't get paid at school, so sometimes I have to negotiate what I will go to. Over time, you get better at balancing everything in life, and you figure out how to make time for school.

Lola, a first generation graduate student, mirrors Chris's experience:

One of the biggest challenges is being able to balance work, school, home and family. Juggling so many things at the same time and feeling like you don't have enough time to juggle everything. So for me, my priority is school. Anything after that gets whatever they can get. I go weeks 
sometimes not seeing my family because I am at work or at school. It's definitely a sacrifice, but because my family supports me going to school, they understand, but there are still those times where you don't get to spend time with your loved ones and that's hard. Even when school is not in session, I still find myself doing a list of things I was not able to do while school was in session. It's a constant catch up game.

Renee, a first generation college student, also shares the same concerns as Chris and Lola:

I work 25 hours, take 17 units, have an internship; there is no "me" time. My "me" time is sleep time. My friendships are affected; I don't see my friends much. I can't remember that last time when I was in school, where there was just a day where I could do nothing and not have to worry about paying for it tomorrow. I can't remember that last time I went out and had a good time. There is nothing but challenges when school is in session, and is excellent because I know that I'm putting in work; I earned these bags under my eyes.

While Chris, Lola, and Renee disclose that they all face difficulties in trying to find a meeting point between stability and instability, they all feel a sense of pride in being a FGC student and having come to accept that this is how their life will be while they are in college. And while there is mostly instability, they are learning how to find balance, and when they do, it is enough of an accomplishment that it provides just what they need in order to keep going.

\section{Strategies for Navigating the Tensions Between Predictability and Novelty.}

After gaining a glimpse into these opposing tensions, I have found that most of the FGC students I interviewed are finding a way to make it all work. While there are more difficult days than others, they are, for the most part, comfortable with having a little instability in their lives if it means they can remain in college. To that end, Baxter and Montgomery's (2006) strategy invites segmentation and balance strategy; by meeting or exceeding the rigors of college and also learning how to accept the tensions that come with the college experience, we must be compassionate towards ourselves and find ways 
to decrease anxiety and stress that is often self inflicted. While there were a lot of similarities in the way FGC students felt, it was also apparent that each student has her/his own way of dealing with tensions and negotiating the rigors of being a college student and maintaining a life outside of school.

The predictability/novelty dialectic falls in line with Baxter and Montgomery's (2006) segmentation and balance strategy; by meeting or exceeding the rigors of college and also learning how to accept the tensions that come with the college experience, we must be compassionate towards ourselves and find ways to decrease anxiety and stress that is often self inflicted.

For Ashley, a first generation college student, a large factor in her success in negotiating school, work, family, and friendships is time management. She says:

As a first generation college student, the main challenge I faced was time management, but working and being a full-time student shows how independent I am. Even though it's hard, it shows that I am making it through, and even though there are many things that I could choose to let hold me back, I don't.

While Rosie finds relief in being able to find time to do the "little" things in life, or what she calls the "big" things in life, she also struggles with wondering if she is going to have any regrets when she is done with graduate school. Rosie discusses negotiation in terms of finding small moments of enjoyment in doing tasks that may seem mundane to the average person:

Things like going to the bank, doing laundry, little things are really big things in my life. It's hard because when you can't do this stuff you feel like you are not living your life. I feel like I am learning about communication studies, but I am not communicating with anyone. I remind myself that I wanted this, but it's still hard. 
Like Rosie, most FGC students struggle with finding a common ground between school and personal life. Regardless of how they cope, students learn to negotiate their responsibilities and locate social support as a way to build solidarity when they feel alone.

\section{Self Support}

The FGC students I interviewed, whether graduate or undergraduate, all expressed feelings of pride at being the first in their family to attend college. But, this pride is precisely why they often fight so much for so much independence in their lives. It is one of the reasons why being "off center" can feel like failure . For many of the FGC students I interviewed, balance is a measure of success. Many of the students in the focus groups shared that they learned how to navigate the university by making mistakes. While these mistakes were painful lessons at the time, they were also lessons that presented themselves as opportunities for growth.

During the interviews, I learned that many of these mistakes had to do with learning how to navigate the administrative side of the university. We like to think we have a superhero quality that allows us to do it all: work, school, home, social life, and relationships; yet, in reality, we cannot do it all. During the interviews, several students expressed feeling as though they knew they were setting themselves up for failure, but they had too much pride, which contributed to an unwillingness to ask for help or make sacrifices. This may eventually result in the realization that we will fail at some point, and we must learn to find a balance between having pride in knowing that we can accomplish a great deal through social support, but also knowing that we will fail from time to time without the assistance of others. However, this does not mean that we have 
failed entirely or that we have failed at being first generation college students. As students expressed not wanting to let their families down, they also described how much pride they take in their position in their family as the first to attend college.

Rosie, a first generation college student in graduate school, describes herself as very driven and self-motivated; she expressed that she pushes herself harder than she probably should:

I set high limits for myself to see if I can overcome them and try not to fail in the process, but failure is inevitable. I work four jobs, and I go to school full time. It's very lonely and it's hard to be in that environment where there is so little time; it's hard to connect with people because you have all those other priorities. These friendships might be temporary or long term, but in order to get where I want to be and where my family wants me to be, I remind myself that I can always make those connections with people.

Rosie stated that she was not aware she had a "to do list" on her MySJSU account, and she was dropped from all of her classes when she did not realize she had "action items" she needed to take care of in order to ensure her enrollment was complete. Rosie describes this experience as:

A really humiliating process because you have to go to every teacher and tell them you were dropped from your classes, and I feel like they automatically assume it's because you're an irresponsible person and student. It's so embarrassing to go to the dean and say that you were dropped because you didn't make a payment when you really did make the payment. But, I found out that if you pay online there is an additional fee, but if you pay at the school, you have to write a check but it had to be during their open hours which are during the times that I work, so I had to take time off work to drive down and pay for school, only to find out that I ended up being dropped from my classes. I feel like there needs to be more accessibility to these things; we should not be keeping the administrative side of college a secret. The well-being of the student is not necessarily always being taken into consideration.

Claire shared that: 
Going to college, I had no idea what to do, and in high school, I was not in the college state of mind and did not realize that it was preparing me for college. Going to SJSU, I have had so many problems because here you don't know something until you find out, and you are screwed because people are not going to tell you that you are going to graduate in four years, and in orientation my advisor told me to take twelve units, but I did not know that you need to take fifteen units each semester in order to graduate in four years. In most cases, you don't know what to do until you mess up, and then you have to go fix it, and it's just frustrating. Going to school and working is hard. I work on campus, so it's more convenient, but I am here all day, and it's just hard because you are trying to get your degree, but you need to work to help support you and your family.

Another theme I discovered from these interviews was that many students made the mistake of not taking their grades seriously. Many FGC students find that college is a much different world than high school, and no one is following up with you to make sure that you are attending class, keeping up with the work in class, or following along the syllabus to stay aware of upcoming deadlines. A majority of the first generation college students I spoke with experience pride through self support at some point in their college career, and this is often a catalyst for the desire to create autonomy. To that end, they also experience failure, and that is often a result of feeling as though they are disconnected from others, ultimately leading to a desire for social support. While the success rate of self-support differs from each student's own experiences, I found through the interviews that every student, to some degree, found that their best resource, at least during the early stages of entering college, was his or her self. And, pride is a contributor to the prevalence of self support in FGC students. This was not a surprise to me, mostly because this was how I learned to navigate the university system. It was not until I was already in my classes and already an "established" college student that I began to reach out for social support. 


\section{Social Support}

Social support is multifaceted and students seek it out in different ways depending on what their needs are. For this study, I identified several forms of social support; listening support, reality confirmation support, task appreciation support, and tangible assistance support (Rosenfeld et al, 1998). Social support is a network between people who communicate in an array of ways to achieve a common goal. This is what makes the difference in working independently on a project or a paper when a student has her/his peers to turn to for assistance. In this way, we are doing what Lancaster (2010) suggests by creating agency for ourselves. The focus group interviews I conducted provided me with a sense that for the FGCs who participated in this research, the role of social support they found most helpful in their efforts to succeed were from teachers and classmates. While their families play a role in supporting them, they were not able to provide them with support regarding topics such as navigating college, understanding concepts in the classroom and learning how to use the SJSU online student database. Additionally, students discussed available to them. In this way, reality confirmation support is sought out. Monique tells me that she took her professors for granted:

In one of my English classes, I kept getting C's on my papers, and it brought down my grade. I am a good student, but I did not have a strong ability to write. The teacher informed the class that we would be allowed to rewrite two of our papers, and it was at that time when I decided to meet with the teacher in her office hours. I realized then that I should have gone to the teacher much sooner.

For Monique, it might have been helpful to have another student to share her perceptions with college courses. 
Social support is necessary for transgressive education (McLaren, 1993). Social support is a large component to academic success and transgressing oppressive boundaries (Lancaster, 2010). Locating social support often comes from the cohort with whom you attend classes. Lancaster urges FGCs toward agency for our own success, as we are ideal in providing social support to one another, whether technical, mental, or emotional support (pp. 77-78). I frequently turn to my cohort for support. It is helpful to hear that other students are facing some of the same challenges that I face; I need to know that I am not alone. I need to know how the other first generation college students are adapting to the new schooling rituals that go hand-in-hand with higher education. We cannot overcome discrimination and hegemonic discourse pedagogically until we become aware of, acknowledge, and include similarities and differences in first generation students' experiences, including social support as part of the communicative process.

Understanding the importance of grades, registering for classes, understanding how to ad and drop classes and discovering the correct amount of units to enroll in were all large topics of conversation in the interviews. Orlando recalls signing up for classes that were not even necessary, but he received bad advice from an advisor in his freshman year. In this way, tangible assistance support would have been useful. Like Monique, Orlando waited until he was near the point of failing a class before he would seek assistance from the professor.

Orlando: I failed numerous classes; I was able to retake them through academic renewal and received A's, but those F's are still on my transcripts.

Students informed me that they often stayed in a class and risked a bad grade because they were unsure how to navigate the SJSU website and did not know what to do in order 
to be removed from a class. Chris found himself in a crisis mid-semester and was earning a passing grade in a class and did not want to drop, but he was forced to due a family hardship that required him to stay home with a family member. This resulted in a lot of missed classes and schoolwork. Chris, found this was a very difficult experience because he did not want to drop the class, but he also knew it was his only option because he did not want to receive a failing grade in the class. Because it was so late in the semester, Chris had to pursue a late-drop. The professor signed off on the request, and the paperwork was submitted within the requested time frame. Because the paperwork was submitted, Chris no longer attended class. Several weeks later, Chris received a letter from the university stating that his request for a late drop was denied, and this resulted in Chris earning a failing grade in the class. It was at this time when Chris really could have used some support, specifically listening support, from another student, a faculty member, or a counselor. Chris felt very silenced during this process and he may have experienced a different outcome had he been provided with a chance to share his story. This was one instance where working independently did not help.

For many FGC students, feelings of isolation began to develop because they struggled to create balance between autonomy and connectedness, and the role of student became a very lonely identity. Because of this, FGC students turned to social support as a way to find comfort in the unknown. Rosenfeld et al (1998) examine social support in relation to they ways in which lower to middle class students whom identity as either "at risk" or not "at risk" succeed in school. While the authors discovered that parents play a large role in social support for "at risk" students, those who were identified at not being "at risk" sought out support from their teachers or friends they attended school with. This 
study also illuminates how educational outcomes differ depending on the types of social support students receive. "Feeling socially supported seems both to encompass a large amount of building academic adaptability and to encourage positive educational outcomes for students.” (Rosenfeld et al, 1998, p. 310).

The students I interviewed said that it is more helpful to find support from those who are also first generation college students because they felt that they would not be judged or looked at differently. Lola describes social support as being an amazing thing. Rosie describes her desire for social support as a response to feeling alone in her experiences. Rosie states that there are "many moments where you feel so unsure of yourself, and you feel like the world is against you." Many of the students I interviewed told me that they did not receive support at home, outside of words of encouragement, and family members telling them "you can do it" or "you made it this far, you can keep going." While words of encouragement provide moments of support, the other forms of support, the kind of support you can only get from those who have experienced college first hand, generally do not come from the home.

Whether or not a student seeks social support depends on the individual student. However, Monique and Charles describe what college life can be life when you do not have the support that you need:

MONIQUE: I did not know that my high school offered assistance; I learned how to navigate the university on my own. My friends don't encourage me to strive for education; they are more concerned about parties. I don't feel any motivation from them, and so I rely on myself.

CHARLES: When it comes to administration and financial aid, I have no idea what I have to do, and I try to ask my parents, and they don't know. And, sometimes we have to ask a family friend who went to college to see if they can help, but most of the time I am just going up to offices or administration looking like an idiot, and I tell them I don't know what I 
am doing and ask if they can help. And, they treat me like I should know these things, but I feel like they need to know that there are first generation college students, and they should know how to help us. It really all goes back to networking and making connections with those people who have already gone through it, so that they can help you.

For Charles, task appreciation support was a large component to feeling validated and appreciated by the university.

CHARLES: I feel like schools really want you to fail and then learn by your mistakes, but some of us don't have the income to be here for five or six years, so I find it really upsetting that they don't really put as many resources into us as they say they do, and I wish they would let us know about the recourses early and not let us figure it out after or its a last minute thing.

In addition to wanting to feel acknowledged, it is also important that students feel they are being provided with locations to their schoolwork, quite often then are not able to find a space at home. Amanda stated that having a place to study can make a difference in whether or not a student succeeds in school; Amanda found that she did not have a place to go to study in her home, and as a result, she often had to go to coffee shops or drive to school to find a quiet place to work. For Amanda, social support came in the form of making relationships with other students and trying to make the best of the situation at hand.

Though these interviews, I discovered that social support is a large factor in contributing to a first generation college student's success. However, the type of social support and how students access it differs. Wednesday finds support through networking in classes. Wednesday stated that this is less frequent now that he is a graduate student, "but as an undergraduate student, there was times where I could not even afford the book, and so I had to network and make friends with other people in the class who would be 
willing to study with me or make me a copy of something. And, without that, I don't think that I would have made it." I also found that first generation college students are hesitant to reach out for social support because they are unsure if others will understand their experiences if they are non first generation students. This reminds me of the importance of dialogue and how imperative it is that students are invited to engage with one another. Regardless of whether or not a student seeks a great deal of social support and becomes connected to fellow classmates or chooses to receive minimal support and find comfort in autonomy, all FGC students find themselves at a point where they appreciate or desire social support.

The Autonomy and Connectedness Dialectic. The journey though higher education can be a lonely one. There is no longer the comfort of high school friends and the familiarity that once was is lost. New teachers, new classmates, and new administration collide at once, creating an experience for which some students are unprepared. All of these elements add to the feelings of anxiety that many FGC students feel as they enter into the culture of college life. While they learn to self-heal during this process, FGC students also rely on their own skills to learn how to navigate the newness they confront. Quite often, FGC students find themselves wandering around campus trying to make sense of everything. This self-navigation becomes very normalized after some time. However, this does not mean that it is easy, or that it is the path FGC students want; the reality is it often feels like there is no other choice, no other support.

When FGC students reach the point where they locate social support and develop connections with their peers, it is a juggling act to figure out how much is just enough and how much is too much, and from whom they are receiving support. Some students 
find that social support is one factor that contributes to their success, while others find that too much social support can be distracting and minimize the rigor that becomes a ritual to those in higher education, and at times, a competitive spark can ignite in the classroom as students begin to feel threatened by those who are assisting them through the maze of higher education. In the interviews I conducted, students mentioned not wanting to share work with others, staying up nights to finish a paper by the assigned due date, and then being frustrated at hearing other students ask for extensions, feeling as though those students did not want to work as hard as those who were not asking for extensions. In this section, I will explore the juxtaposition that students face with feeling accomplished for being self sufficient, while also seeking out social support as a means of decreasing feelings of isolation.

FGC students often enter college with the expectation that they will be on their own. This is mostly learned behavior because as FGC students, we have no one to assist in the process of applying for college, registering for classes, or navigating financial aid; so, we often approach learning to navigate the administrative side of college in the same manner. When I asked FGC students how they learned to navigate San José State University, the response was mixed; some students found help through advisors at their high school or community college. Other FGC students sought assistance from programs like EOP and AVID; for others, it was complete trial and error. Lola stated that she received direction from her advisor at the community college she attended prior to transferring to San José State:

My advisor showed me everything that I needed to know in order to transfer, and she showed me how to go online and navigate that aspect of the university. But, it is really trial and error and knocking on every door, 
going to every person, asking the same questions until I was directed to the correct answer.

Rosie echoes Lola in stating that:

It was complete trial and error for me too. I made friends in community college who transferred here a year before I did, so when I had questions, I went to them, and one of them was a first generation college student, and she helped me. I remember transfer day here, and I was introduced to communication studies. That is how I ended up in this department and meeting a professor who was helpful and guided me. But, I was really lucky to have friends here; I feel like if it were not for them, I would not be here.

While some students relied on themselves for a majority of their college career, they discovered, through gaining some assistance from friends or advisors, that though they were self-navigating the university, they took comfort in being a part of such programs as the Educational Opportunity Program (EOP).

WEDNESDAY: The administrative part of it is difficult, and there is so much paperwork, and they lose it. I feel like it is just a step, a roadblock to put in my way, and I don't get that.

MONIQUE: Orientation definitively helped me learn how to navigate SJSU. Also, being a part of EOP helped me a lot. In order to participate in the program, I attended workshops that helped me navigate the university and not feel so lost.

Keith, one of the FGC students I interviewed, is an international student from China.

Keith found that because of his status as an international student, he received more orientations and assistance while he was studying abroad. Keith stated that his "status as an international student was like the international gateway to the university; you have a lot more orientations, and I received a lot of help." Unlike Keith, many of the FGCs in the focus group interviews are not international students. The majority of the population did not receive a comprehensive orientation and shared that their quest for social support was in response to their desire for a deeper emersion into the college culture. 


\section{Strategies For Negotiating Tensions Between Autonomy and Connectedness.}

Participants reported that they negotiate tensions between feeling as though they are on their own and feeling that they need access to social support, so they do not feel so isolated and lonely during their college experience. Students also report that while social support is helpful, it can also be a source of tension because they are cautious about whom they go to for support. Strategies that FGC students use to negotiate tensions between autonomy and connectedness are closely related to Baxter and Montgomery's (1996) notion of integration, which is a response to opposing tensions that involves being fully present and responding to all opposing forces at once, without having to make a choice between the tensions or having to find a compromise.

I also found that in most cases, students did receive some form of social support from their peers, professors, and/or counselors however, they were unaware of it because the definition of social support is complicated. For the purpose of this study, and to reference Lancaster's (2010) study on first generation graduate students and social support, I will use the Rosenfeld et. al. (1998) definition of social support as communication that increases personal control and decreases feelings of uncertainty. This means that social support can be communicated in several ways: advice, financial aid, or the presences of another person (Lancaster, 2010, p. 11). Ashley, along with Monique, received social support in the form of the EOP.

For FGC students, this means acknowledging that both autonomy and connectedness are necessary in order to feel fully engaged and self-reliant. Several FGC students stated that a mixture of self and other was what contributed to their overall success thus far, and that these go hand in hand; it's a combination of self-exploration 
and reaching out to the correct individuals to ensure they are receiving the necessary

resources. Lola recalls her strategy for gaining support as both relying on herself and reaching out to professors, stating, "I received incredible mentorship from my professors, but that came to me after reaching out them and asking for help." Renee describes his strategy for finding support as:

My friends and family were the number one resource for me; though I did not receive any financial assistance. I knew I had the support of friends and family.

Orland describes his strategies for negotiating tension of autonomy and connectedness as receiving too much financial assistance and not being told he much money he would or would not need to finance college. This is an instance where social support was not necessarily helpful. Orlando explains:

What I received from being a first generation college student is loads of student debt. I didn't have anyone telling me that I did not need to take out that much money, and I didn't qualify for financial aid, so I had to figure out a way to pay for school because I did not want to burden my parents.

CHARLES: There are stereotypes that FGC students always get the financial aid, and that's great. I am one of those students, but I wish we received more class opportunities or priority registration like EOP gets because other FGC students at other universities get it, and it seems like we want to graduate sooner than non FGCs. I wish there was more guidance in processes in administration, and dealing with administration, and more information about what is going on their campuses.

While Rosie explains the opposite:

Money would have been great. My parents encouraged me to take loans, but I did not want to. I did not want the debt or burden of a loan. So, I have to work four jobs to pay for school; I pay for it fully, out of pocket.

However, this was not an option for all first generation college students because the qualifications to get into the program are based on low-income status. The admission 
process is similar to financial aid in that you either get the support or you don't, and if you don't get the support, taking out loans or working several jobs may be the only other option for financing college. Dianna was a part of a program in high school called AVID. This program assisted her with the college application process, navigating financial aid, and registering for classes as well as connecting her with other first generation college students.

Connectedness through social support comes in many forms, but it is also combined with autonomy through self-reliance. It is the integration of the two that seem to be the best strategy for FGC students. As many students learn to integrate self and other as a way to gain success while navigating the maze of higher education, students disclosed that these experiences have a great impact on their communication in the classroom and affected their decision to disclose her/his status as a first generation college student.

\section{Disclosure}

FGC students experience numerous dialectical tensions specifically in a classroom setting, a predominant tensions that emerged during the focus group interview was that students were conflicted in deciding whether or not they would disclose their status as an FGC to other students. Many of the FGC students I interviewed discussed uncertainty in disclosing this to others and struggled to find a balance between feeling privileged that they are first generation college students and feeling oppressed and feared they would be labeled as "different" or "at-risk" if they shared this identity with their peers or with their professors. When asked whether or not they disclosed their identity as FGC students, the responses varied. Some students stated that they do not disclose it 
because they don't want sympathy and they don't want anyone to feel sorry for them.

However, others expressed a great deal of pride in the status:

AMANDA: I never heard of the term until a few years ago. I also never felt like I had to tell anyone and also did not want to be cast as "different" by other students. I never felt like I wanted to "out" myself as an FGC. However, if I felt like I had it in common with someone, I would share the status with him or her as a way to build an alliance, but I am not sure I could do this with students if I did not know they shared the identity with me.

CHARLES: I don't say it unless someone asks; I don't feel like it is a big deal now days. There seems to be a lot of first generation college students. It is a bigger deal to my family and me than it is in school. But if people ask I will tell them; I am proud to tell them but I don't think it's necessary to tell them. Regardless of our race, age, gender, ethnicity, we are all in college.

DIANNA: I am not ashamed that I am first generation, but I don't brag about it either. It if comes up in conversation, I will talk about it, but I don't want to say anything and have people think that I am trying to get something out of it or that I want special treatment.

While Amanda, Charles and Dianna are hesitant to disclose their status, and tend not to state it unless they are asked or know of others who are also first generation college students, other FGC students I interviewed were more forthcoming about their identity:

ORLANDO: As an undergraduate, I never had to say anything; people would just look at me and assume that I was first generation. However, as I progress through higher education, and now that I am in graduate school, people assume the opposite, they assume that I am not a first generation student. If people ask, I will tell them because it is something to be proud of. But, other first generation students that I come across don't disclose it because they feel it's a stigma, but I don't think it's a stigma.

CHRIS: I don't mind saying it because I am proud, but at the same time there is a stereotype that goes along with it that maybe we are not as good of students as those who are not first generation. Teachers might feel we are not as intelligent. It depends on who you are talking to and the open mindedness of the person, if they are willing to just focus on the stereotype than it might not be worth telling them, but if they are willing to have an open mind then I don't mind telling them. 
Keith, a first generation college student and an international student, offered a response, which encapsulates most participants' perspectives:

Basically, I don't. But if someone asks me, I will tell him or her. It's like the Lady Gaga song; "I was born this way," so I don't have a choice and everyone has his or her shining moments.

For Amanda, Dianna, Orlando and Chris, the impact of disclosing their status differs. Keith offered up a response that I think most FGC students can appreciate. While it is not at the forefront of their minds every time they walk into college classrooms, it is an identity that is a part of who they are. While most FGC students do not intend to hide behind their identity, they seem to take more comfort when they know that there are other students in the classroom who may share their story or who may have an idea about their journey as college students. Additionally, the reasons students stated that they do not disclose are less about feeling discomfort in their identity and more about fearing the stigma and negative discourse that seems to attach itself to FGC students. A large population of the FGC students I talked to were open in telling me that they not only struggle with feelings of oppression and/or marginalization in their identity as an FGC, but they also struggle with identity management and learning to accept that not all parts of lives will come together as well as others. While some students disclose as a way to combat feelings of oppression and marginalization, others turn to silence as a way to overcome similar tensions.

\section{Silence}


The rhetoric behind silence is often heavily influenced by personal experience and cultural background. After conducting the focus group interviews, I found that silence often weaves itself through privilege and oppression, and students can make active efforts to remain silent, or they can treat silence as a shield to protect them from feeling "unsafe" or exposed in a classroom. While some students make an effort to remain silent, others feel as though that is a privilege that is not afforded to all FGC students. Hao (2011) offers value to silence in dialogue as some students create agency through their silence; for them, it is an active rhetorical strategy. Hao asserts that silence does not mean students do not have a voice, and silence can be a dialogic exchange if allowed. However, U.S. classrooms heavily emphasize oral participation as a classroom expectation (Hao, 2011, p. 268). Lola stated that she feels insecure in the classroom, and as a result, she really does not say much:

I keep quiet because I feel that if I speak up, someone in the room will lash out at me and disagree with me and I just don't want that confrontation, so I keep my comments to myself.

Regardless of the rhetorical strategy, first-generation college students must learn to find their voices within their studies. By finding their voices, they learn to develop arguments, participate in dialogue, and analyze ways to contribute to their area of study. As a result, FGC students are often more successful through their use of voice, than through silence, but this is a learned behavior, a privilege afforded to a select population of FGC students because they may not have a reference point for how to participate in a college classroom.

Narrowing the understanding of these students and their needs eliminates the possibility of creating dialogue, and without dialogue, we cannot continue to increase our 
knowledge about identity(ies). "We would do well to remember that identity is not easily compartmentalized; one cannot separate who one is in the workplace from who one is in the classroom, any more than a researcher can separate herself/himself from what s/he studies" (Fassett, 2005, p. 253). hooks (2003) urges for a democratic education; this framework assumes that learning expands beyond the walls of a classroom. By embracing dialogue and the concept of democratic education, we can begin to move forward and further develop current research on first generation college students. Just as there are times of struggle for FGC students in college classrooms, there are also times when being an FGC can help the ways in which one communicates in the classroom. Wednesday, Charles, and Theo share their experiences where being an FGC provided them assistance in a classroom:

WEDNESDAY: I feel like as a FGC student, I value education sometimes more than other people because I remember in my fraternity days, I knew I was different from the students whose parents were paying because they did not go to class as much and got to have more fun in college because it seemed like they did not care as much. It bothers me when people don't value something when people are working so hard just to get in the door.

CHARLES: I benefited being a first generation because I have taken courses where teachers are happier to see FGCs in a classroom setting and they push you more and help you get through things and feel like you can do it. There are also other times where it does not help and teachers do not understand, so it is a win-lose situation with teachers, being a FGC in a classroom.

I don't want to make students who are not first generation look bad, but I feel like FGC students are more hungry and want these classes more than non FGCs, and I don't want to generalize that, but I know a lot of friends who are FGC, and they really want classes, and there are other kids who are just coasting through, and they know that they will be ok, and that they will be taken care of unlike other students, FGC students who have to work harder to succeed and they don't have the ability to be here for a long time until they figure out what they want to do. 
THEO: I do work at the student learning center, and I work with FGCs and non-FGCs and the ones that are not FGCs tend to talk about homework and not want to do it, but for the FGCs they know they have to do it. It just seems like there is a different outlook from those who are FGCs and those who are not.

Since FGC students are the first in their families to attend higher education, they are a part of a culture whose background does not fit a traditional role in academia, and the feeling of oppression through silence manifests in different ways, depending on the individual. Wednesday recalls how remaining silent was a privilege for some students, but not for Wednesday.

If I did not understand something, I could not afford not to ask a question because when I got home, there was no one to turn to, and if my friends didn't know, then I would be left without knowing what was going on.

Hao (2011) asserts that silence is a privilege of Western culture. Yet, silencing students and having students in the class who are silent are not one and the same. Silence is often perceived as an academic deficiency, and the assumption is that it prevents students from engaging in dialogue and thinking (Hao, 2011, p. 268). As oppression came up in the interviews I conducted, it was clear that these feelings stem from the classroom and the ever-changing dynamics of what a given classroom looks like, what the teacher is like, what the students are like, and how "safe" a student feels in the space.

The Openness and Closedness Dialectic. The openness and closedness dialectic emerges from the intersection of students experiencing tensions of oppression in the classroom through silence and experiencing tensions with feeling privileged in the classroom though disclosure. During the focus group interviews I conducted, students told me that while they do not always feel as though they "fit in" with college culture, 
they also find themselves in a place of privilege because they are college students, and that is more than they can say for any other member of their family. So while there is a struggle at times, students feel that they need to be more conscious of their educational journey(ies) and become more liberated in college classrooms.

When asked how they felt about being the first in their family to attend college, students expressed mixed emotions. Renee says:

I felt very fortunate because I know a lot of people are not able to attend college. I know that I am blessed, and I feel that I have to lead by example and finish strong.

Ashley states that:

Being the first in my family to attend college is scary. My parents are immigrants from another country and do not know much about the college system in the U.S. I have felt very on my own throughout the entire process.

Chuck says:

There is a large amount of pressure, and I feel like if you don't get into college or get a degree you can't make any more or do anything in today's world. I am just in college to get a good degree and great job so that I can help my parents retire. I feel like that's why I want to go to college but at the same time it is a lot of school and I have a hard time learning from the book, I learn better by doing things than by reading about it.

Of the FGC students I interviewed, some reported they would have felt more liberated if they knew how to navigate the university more successfully. Not all the students feel that education is accessible, even after they have been accepted into college and are active students in the university. While universities count the number of FGC students who are enrolling for college, they tend to use this information to look at the rate of FGC student drop out and often resulting in this population of students being labeled as "at risk." What the universities are not taking into account is whether or not these 
students receive the necessary tools to gain access to the ways in which students navigating college.

CHUCK: I came from small school throughout my life, and so all the classrooms were always small. From what the movies I saw growing up, college was always like a lecture hall with millions of students and one teacher, but it's kind of like the opposite here, the classes are smaller. But, I feel like I don't talk to people as much as I used to, and I feel like I can't connect on the same level as you would in high school and middle school because everyone is a different age, but I also feel that it is good to network so I have to put myself out there more than I did in the past.

During the interviews, students reported that the more access they had to navigating the university system, the more chances they had for succeeding in higher education. So while counting students has its place, it simplifies the experiences of countless first generation college students and creates a dialogue that is often untrue about this population of students, about how "at risk" these students are in a space that has not been traditionally occupied by their family members. It is imperative that students know how they are being counted and that universities' provide resources to these students to succeed instead of counting them and reporting drop out rates.

Institutions of higher education must provide context behind their attrition rates in order to show why these students are not succeeding. Freire (2000) asserts that education provided by the ruling class is necessarily hegemonic, but if educators truly care about who they educate, then education can become a socially liberating practice. A majority of the FGC students expressed feelings of oppression, specifically in the classroom. hooks (2003) tells us that silencing is the most oppressive aspect of middle class life. hooks goes on to assert that education should be a socially liberating experience, open to all. "In order for education to truly liberate, it is necessary that it is accessible to those from 
backgrounds who have not traditionally pursued higher education" (Lancaster, 2010, p.5).

These words remind me that education, on all levels, is a privilege as it is only available to a community of individuals who have the means of attending, financing, and completing the rigors that higher education brings. I experience education as a privilege because I am not only a first generation college student, but also as a middle class student who regularly struggles with feelings of discomfort in the classroom. As I sit in a classroom as first generation college student, there are countless numbers of students who do not receive access, or are not invited to join in this same opportunity. A majority of the FGC students expressed feelings of oppression, specifically in the classroom.

\section{Strategies for Navigating the Tensions Between Openness and Closedness.}

FGC students negotiate tensions of openness and closedness by taking pride that their place in academia holds great value in their life, while also acknowledging that because they come from a background that is not traditionally rooted in higher education, feelings of oppression are destined to show up from time to time. As such, FGC students take on Baxter and Montgomery's (1996) strategy of spiraling inversion (allowing his or herself to feel each of these tensions), acknowledging that a given contradiction is more dominant at a given time, and not sacrificing one for the other.

FGC students generally feel the implications of silence as they enter into academia for the first time, and as they progress, a student's ability to disclose develops and becomes a part of the culture of higher education. And yet, even as FGCs recognized privilege, one's feeling of being silenced, whether for a moment or for a long period of time, cannot be denied. Many of the FGC students I interviewed shared the ways in which their access to higher education is a privilege that they will not give up, even if that 
means working four jobs, sleeping two hours a night, and compromising friendships and time with family members. Several students shared stories where they felt as though they were going to graduate from college and enter into the "real world" without much of a social circle outside of those connections they made in college. And yet, they acknowledge that there are students who would sacrifice everything to be in their position. So while there is an occasional complaint, frustration, or sleepless night, these students are all aware that this is something that should not be taken in stride. While in the ebb and flow of oppression and privilege, there is great passion behind whichever is holding particular dominance. Finding fluidity between the two is what allows FGC students to invite functional patterns of spiraling inversions as a way to negotiate opposing tensions.

In this chapter I addressed two research questions: RQ1: How do first generation college students communicate dialectical tensions in the classroom? and RQ2: How does a first generation college student's access to navigating college contribute to success in higher education? These questions guided me throughout my research; I have identified three common tensions that emerged from the focus groups I conducted (stability and instability, independence and interdependence, and oppression and privilege). In my effort to create a dialogic exchange between the FGC community and focus groups, along with remaining reflexive through this study, invited a great understanding for the experience of FGC students. And they revealed how their ability to navigate the university holds great significance in their experiences as students. While similar to traditional college pathways in many ways, being a first generation college 
student is overall a vastly different journey and situates dialectical tensions at the root of classroom communication.

In this next chapter, I aim to provide implications for my findings thus far. I will illuminate the ways in which a FGC student's success in higher education has less to do with their "at risk" factor and more to do with how much access they have to navigating higher education and how dialectical tensions emerge in classroom communication. I will also stress the importance of changing the ways we approach this particular student population. Finally, I will provide recommendations to address the issues that emerged in my research for first generation college students, faculty, and universities, specifically the administration. I will then discuss the strengths and limitations of this study and share my hope for areas of future research that can continue to provide guidance to first generation college students. I will also share a final personal experience in hopes that other current FGC students, or those who are considering enrolling in college as an FGC student, gain some insight into the lives of other FGC students who have embarked on this remarkable journey, succeeding against all odds. 


\section{Chapter Five: Implications}

It's the middle of the semester and I have received an invitation to attend the first annual college night for first generation college students. I attend with some hesitation because my participation in this event will "out" me as a first generation student to people I may or may not know. Also, as a graduate student and graduate teaching associate, I face having to decide whether I want to be seated with other FGC students, or with faculty. Since my identity as a FGC student is what brings me to this event, I decide to fill out a blue nametag, indicating that I am a student. I look forward to being seated with other FGC students and hearing about their journeys through the maze of higher education. As I enter the space, I notice several tables labeled "faculty" and a few tables labeled "student." As I take my seat at a student table, I quickly realize that faculty members are the dominant presence. I take a quick head count and guess that there are only about ten to fifteen students at this event, about half of whom came with their families.

I am not immediately concerned and assume that some students are probably running late and will arrive as the presentation begins. As time goes on, I begin to feel frustration and confusion at the low attendance by students at this event. Why wouldn't more students attend? There must be more than fifteen FGC students on campus. My frustration at the students eventually begins to shift towards the faculty. If there are so many of them here, surely they had the means to share information about this event with students. I am puzzled by the lack of FGC students in attendance and, as the presentation continues, I feel a great sadness overtake me. I am reminded of how necessary it is to increase and make more visible the body of research surrounding the FGC student 
community. In the middle of feeling frustrated and saddened, I realize that this is not the students' problem, nor should I be frustrated with the faculty in attendance. This is, after all, the first annual FGC student night. As much as it is a problem that it has taken this long for these students to gain recognition within the university, I am pleased that on some level, it appears that this is changing. So, while I sit here and wonder where all the other students are, I am forced to recognize that in order to create action within the institution, in order to hear the voices of FGC students, we have to start somewhere. Like many of the FGC students I interviewed, I appreciate being recognized for my achievements, and while I do not expect special treatment for being a FGC student, having access to other FGC students and being recognized by the university as a something other than a statistic provides me with a sense of hope that change is coming. Perhaps there will be more attendance by FGC students and their families at future FGC events.

While I am hopeful that the perceptions of FGC students are changing within colleges and universities, it is important to illuminate the ways in which faculty, administration, students (FGC and non FGC), and communication researchers can provide support and guidance to FGC students. There is a great value in recognizing student bodies that are largely misrepresented and misunderstood. We must work hard to change current dialogue, deepen current understanding of FGC students, and make positive changes towards access, retention and graduation, to be more inclusive of this student population. There is a great value in recognizing student bodies that are largely misrepresented and misunderstood. 
I came to this research because of my experiences as a FGC student; this study would not be what it has become without my experience of great angst in learning how to navigate higher education. To that end, I also feel extremely fortunate to be a FGC student because I have the opportunity to share my journey with others regardless of their status. I hope that this study will inspire all FGC and non-FGC students to follow their educational goals and strive to beat the odds (e.g., at risk, low income) that are often bestowed upon them by society prior to even completing their high school education.

\section{Implications and Recommendations for University Administrators}

This study serves as a response to an increasing population that is all too often underserved and unrecognized. There has been an enrollment increase of FGC students due to efforts of universities to recruit more low income students (Heinz-Housel \& Harvey, 2009, p. 13). I, along with the students in the focus group interviews, urge universities to attend more fully to the needs of FGC students and non-traditional students, including financial aid, academic achievement gaps, on campus employment opportunities, academic environment, tuition increases, housing, and academic skill assessments to ensure students who are being admitted can succeed. They must design courses that are accessible to members of the immediate community who are applying directly out of high school or transferring from community colleges and those who are returning to college later in life, or returning for a career preparation. Through my focus group interviews, I came across several resources that students would have like to have received in their first year of college. Below I will outline a plan for success that these FGC students would like to see offered at their university, or where these programs are already in place, promoted transparency. 
FGC Orientation. Family night for FGC students is helpful, however, simply hosting a night for FGC students and their families is not enough. None of the FGC students who participated in my research knew that such an event existed. Furthermore, the event was in the middle of the semester, when FGC students were already progressing through their first year in college and may be at a point where they are relying on other resources for assistance. Where Family Night is positioned as an orientation to the culture of college, it will be more beneficial to students at the start of the semester and should be available to all incoming FGC students, whether community college transfers or incoming freshmen.

Attending Family Night was an illuminating experience, and I gained a great deal of insight into the types of assistance FGC students and their families' need upon entering college. Lola was one of the students at Family Night and she recalls her experience as very discouraging.

LOLA: I went to a first generation college student event here on campus, and there were about 25 people there: 20 of which were teacher or counselors, and there were very few students there. It was disheartening to see how few students there were; there has to be more than 5 first generation college students on this campus. So, the attendance at this event really spoke to the disconnect between first generation college students and faculty and administration on this campus.

After completing the focus groups, I gained more knowledge into what resources students would like to have. Most of the requested items are topics (e.g., how do you register for classes, how many units do you take, how do I select a major) they would hope to find in a typical orientation.

Although Family Night type events are a step in the right direction, more needs to be done in this area if family nights are going to be offered to FGC students and these 
events need to be geared towards a diverse audience, not only those who fit the stereotype of what a FGC student might look like. FGC family nights can often be sources of anxiety and intimidate members of the first generation family (Lowry-Hart \& Pacheco Jr., 2011), I was saddened to see that little effort was made at the event to ease discomfort the attendees may have been experiencing and the amount of faculty presence likely did not ease nerves. One faculty member suggested that students "get their teachers to like them" and that if you tell your teacher you liked their lecture, you are more likely to succeed in their class. This is some of the advice that was being provided during the question and answer portion. I heard a lot of suggestions about they ways in which students can approach their teachers, but I heard little about what teachers can do to gain trust with students or what the university can provide to students to increase their access to available resources. Family night needs to be about access and should offer a virtual tour through the campus. Instead of providing links to recourses, administrators who oversee these recourses should be present at family night in order to answer any questions students might have. I was expecting to arrive to family night and witness a panel of "experts" who to provide detailed information to students and their families. Instead, there was a handful of faculty members discussing the ways in which students could succeed in their classrooms, but that does not ensure success in all college classrooms.

It may be that family nights and orientations are not providing students with everything they need in order to feel confident in their ability to succeed. One reason is that students who transfer in from community colleges do not receive the same orientation as incoming freshmen. Rosie transferred to San José State University from a community college she shared her experience with being a transfer student: "I received, 
nothing, nothing at all. I transferred here, so I didn't get an orientation on how to be a SJSU student, which is different then being a junior college student." Another reason is that the orientation that incoming freshman get is not inclusive to all students in all majors. The orientation is very general and provides a great deal of information on helpful website links but fails to address skills FGC students need for the first year of college, including how to select courses, make a schedule, choose a major, and locate an academic counselor. As Chris states:

On the day of orientation they tell you about the writing center and other programs on campus, but they don't really go beyond saying check it out, click on this link, and see it for yourself. It is pretty intimidating because there is so much to these services and trying to figure it out all at once by yourself seem impossible. Faculty members at orientation use language in a certain way that does not make sense all the time. They set you on your way; you're on your own, and it gets really confusing fast, especially freshman year. Then, when you become a sophomore, you begin to feel a false sense of security; they tell you to pick a major, but they don't explain the process of declaring a major, so I had to figure that out on my own. I feel like the opportunities are here, but they are not explained well enough for us to completely understand them, and it makes them very confusing.

Chris's experience is not unlike many of the other students in the focus group interviews. Rosie was a transfer student who felt she did not receive enough guidance. Rosie states that "it would have been nice to have some sort of mentoring with someone who can tell you how to live in this environment, not die in this environment. Even a page online with quick tips, facts, that would be amazing." Lola would have liked to have received some type of orientation or welcome packet that provides a breakdown of what resources there are, where they are, and how to get them, whether counseling or other programs helpful to first generation college students. Lola shared with her group that she had no idea there were programs like EOP or AVID until she was already in her college courses. In 
surfacing this concern, my goal is not to recreate the orientation process at SJSU, but rather advocate for an additional orientation to campus life for FGC students. Whether they are entering the university from high school or transferring from a community college, the process of learning how to navigate higher education is a daunting task, and for many, it can mean the difference between success and failure. I propose that campuses provide both a FGC family night and a separate orientation for FGC students. While this could be offered to all students in additional to the traditional orientation, it would be optional for those students who feel they received adequate acculturation into college via high school counselors, EOP, or AVID. The additional orientation could provide a hands on approach where students not only take a campus tour, but also meet the people behind the counters at the admissions office. This would allow students to physically walk into the financial aid office, the bursar's office or the counselors' office instead of just having someone point towards the building where these services are located. Navigating a college campus can be daunting for some, but if students become familiar with the layout of the school, any tensions they may be experiencing can be eased by the adaptation of a supplement to the current campus tour.

FGC Guide to Navigating the SJSU Campus. Gaining access to campus and community recourses was a common theme in the focus group interviews. Colleges face an uphill battle to convince students to access the resources needed to ensure academic success, although FGCs understand the value of such services, the ways in which they are marketed to students and the implementation of the resources may need to reflect students insecurities and fears instead of singling them out as different (Lowry-Hart \& Pacheco Jr., 2011, pp. 65-66). FGC students fluctuate between wanting more support 
from educators and the universities they attend and wanting to blend in with the rest of the campus population and not be "called out" or separated from non FGC students because of their status, as a result, they often remain quiet when they need assistance on rely on their instincts to navigate their way through the newness of college. Rene recalls printing out two campus maps, keeping one in the back pocket of his pants and putting another at the front of his binder along with his class schedule. Chuck routinely checked the maps posted sporadically around campus, and when a map was not nearby, he would ask other students where certain building or departments were located. This worked for the first week of classes because many other students were also trying to navigate their way around campus. Weeks later Rene was still utilizing his map and Chuck was able to locate the buildings where his classes were located, but trying to find anything else on campus was still a puzzle. While some students found familiarity in carrying hard copies of campus maps, other students preferred to utilize online tools as a way to navigate their way through the university.

The SJSU website offers a great deal of resources, but locating them is difficult. It is hard to know which page leads to which topics, and it is even more difficult to locate the resource page for first generation college students. After several fruitless searches, I was finally able to locate the page dedicated to FGC students under the academic counseling toolbar, but it was buried with a lot of other important topics that all students should know. Charles wishes there had been more guidance in the processes of navigating college once you are enrolled in your coursework. Charles stated that he didn't know how to use MySJSU; he was a transfer student and had to ask his friends how to use it. When they were not available, he had to "just wing it." Charles believes 
that the school should do a better job of teaching students how to use their resources, without regard to the student's status. There are several ways in which the SJSU website could be improved: 1) Make a more clear declaration that there is on campus support for FGC students. Add a banner to the main page of the website or create a more direct link to the information. The current FGC student information on the SJSU website is located under counseling services, which is not an obvious location for it.

The locations of information need to be more intuitive. For example, place the information for FGCs under the "future students tab" and or the "current students tab." This would allow for FGC students to clearly see that they are an active part of the SJSU campus and that there are recourses available to them. 2) On the webpage that welcomes new Spartans, there should be a link to the FGC student family night information; this would also be an appropriate location to post information on a FGC student orientation, should the school provide one. There is a FGC student presence on the campus, but it is not clearly reflected on the website. In order for students gain confidence and prepare themselves for college, s/he must first have an understanding of what is and is not available on their campus.

If we do not offer FGC students the necessary tools to succeed when they are attending the university, then we cannot expect their attrition rates to change. Instead of accepting students into colleges and just throwing students, who may or may not be prepared for the rigor that higher education brings, into classrooms we must first make sure the university can support the student population, specifically those who are counted and labeled as "at-risk" — often the marginalized, underserved, and low-income students who also identify as part of the FGC student population on campus. These are the 
students who are in greatest need of assistance and access to resources, and, all too often, these are the students who are let down and overlooked by the very colleges they attend.

FGC Student Acculturation to College Life. Much of the rhetoric that surrounds the FGC student population is lacking depth and appreciation for what these students bring to a college campus. They are frequently misunderstood and overlooked, and this has a great deal to do with the fact that all too often these students are fearful of speaking up because they are not confident in their position as students. Becoming accustomed to college life is a challenge for anyone. But, for those students who cannot share this experience with their families, the journey can be that much more challenging. Acculturating to college life and understanding faculty expectations is often not something we teach to students; it is learned behavior, and if it does not come in college preparatory courses in high school, then this skill set develops in college classrooms where first year students are often taking courses with peers who are further along in their college careers. If universities do not teach college culture in their orientations, and if there is not a specific class that looks at FGC students' acculturation to college culture, how are educators and educational institutions to assume that this is common knowledge? I fear that a large reason why so many FGC students are not succeeding in higher education is because they get lost in the shuffle of college and instructors take their silence as disinterest. Students see their instructors as being unapproachable without making an effort to approach them.

Supporting the success of FGC students is extremely important and can play a role in how they come to understand what it means to be a college student. One way universities can acculturate students is to provide them with a roadmap to success during 
their first week of classes. This roadmap can contain specifics such as how to succeed in your first college course, how to communicate with professors face-to-face and via email, and how to gain access to such topics as scholarship information, financial aid, and the importance of grades. These are all topics that surfaced in the focus group interviews, and they are all aspects of college that are often realized either when students are nearing graduation or are put on academic probation. In order to see higher success rates for FGCs in college campus across the nation, universities must play a larger role in making their resources known to their student bodies. I would have benefited from having a mentor assigned to me during my first year of college. A mentor could be someone who has successfully succeeded in college, is an FGC student, and/or may have experienced some of the same tensions and difficulties that go hand in hand with being the first in the family to pursue higher education. Having a mentor would have provided me with a sense of comfort because I would know that I was not alone and I would also have a contact, outside of the university administration, to reach out to in the event that I had any questions or had trouble navigating the college culture. A majority of the students agreed that their first year at SJSU as a FGC student was the most difficult and, in many ways, determined how successful they would be in the years ahead. Being assigned to a mentor could help ease some of the sting that the first year in college might bring.

I struggled with writing this last section because a lot of the recourses I discuss are a part of the on campus programs offered at SJSU. The FGC program hosts workshops for students to attend throughout the semester, EOP offers FGC students access to advising, there are academic counselors available at the admissions office, there is an office specifically dedicated to financial aid assistance, and there are online tools, 
such as the FGC student webpage, dedicated to resources that FGC students may find helpful. Implementing programs for FGC students is not the problem; the problem is that these resources and programs are relatively inaccessible: very few FGC students know about them. These programs need to be more visible and presented in ways that are not intimidating to students. Universities and educators should not assume that students are acculturated to college life on the first day of school; we need to do a better job of understanding the positionalities of these students in hopes that they will create agency for themselves if the opportunity presents itself.

All FGC students in the focus group interviews I conducted discussed their hesitation in identifying themselves as FGC students, but they also stated that they felt they needed support from the university and from their instructors. In order to provide the level of involvement that FGC students need, it will take dedication, perseverance, and compassion towards helping these students negotiate the tensions that arise from managing dialectical tensions in their first year experience and learning how to navigate higher education in general. By providing FGC students with the necessary resources that they will need to be successful in college, we are ensuring they will have access to a support network: a university system that is more accessible and educators who have a greater understanding of what it means to be a FGC student. In the end, this will create space for their success and open doors for greater opportunities in higher education. It will help students build more confidence in his/her self and help close the gap between the openness closedness dialectic. 


\section{Implications and Recommendations for Educators}

This study provides helpful in developing a guide for some ways FGC students can manage tensions as they learn how to navigate higher education. However, I also found that my research offers useful insights for instructors. In particular, there are opportunities for teachers and FGC students to work together in creating a successful college experience. For educators, I offer a reconstruction of class identity in the classroom, a cultural orientation, if you will, and a way in which instructors can offer "behavioral expectations of academic culture and expose invisible expectations they have of students." (Lawless, 2008, p. 24). Educators can achieve this by examining how we normalize expectations in higher education. Lawless (2008) asserts that class intersects with other identities, making it difficult to define in singular terms; these intersections can enter into the classroom and become a factor in whether or not a student is able to succeed. This was true for the focus group participants I interviewed. For example, instructors may have a tendency to unconsciously take certain beliefs and values for granted and question systems of "the other," implicitly placing their own values in higher regard. Amanda spoke about her lack of confidence when speaking in a college classroom and feels like she will be judged or looked at as incompetent because she does not sound scholarly when she speaks. This is at times, associated with classism because the assumption is that lower class individuals are uneducated.

Amada and Orlando felt very judged in classrooms and in some cases, their teachers did not go out or his/her way to change their perception of the student. Orlando shared that he was always very quiet in classrooms because he did not believe that his 
professors cared what he thought or would assume he was a slacker if he did not turn his work in on time, when in reality, there is probably something going on in his life that he is not comfortable sharing with the teacher. It is an injustice to make assumptions for others, and expecting them to want to strive for middle or upper class status, which is often equated with success and failure. Instructors who enact classism in their classrooms need to become more aware of the ways in which their actions can marginalize the FGC student community (Lawless, 2009, pg. 29). hooks (2009) describes what it was like to watch her conversations with friends and family shift after entering college. I have also watched this happen in my graduate cohort and experienced this first hand. Educators can reflect on their own class-based assumptions and resist classism by creating more inclusive environments in their classrooms, reaching out to students who may appear to be disinterested, and provide a sense of familiarity in the classroom by outlining the objectives for a given class period, or by sharing expectations with the students throughout the semester.

Several FGC students in the focus group interviews also shared feelings of confusion and disorientation towards locating a place of familiarity in higher education and also feeling as though they adapted a language and culture that is no longer accessible to their family and friends. "When FGCs learn the rules of higher education, they start to use academic jargon, think more critically about themselves and their position in society" (Lawless, 2009, p. 27). As students, we enter with ideologies we associate with our cultural upbringing, and when we enter college, we explore what it is like to be a critical thinker, learning to think in ways that we may have never thought before, and some students develop thoughts and beliefs of their own for the very first 
time. Because of this, it can becomes difficult for some FGC students to code switch between worlds; this creates tensions between the classroom and home that can greatly affect the ways in which students learn, understand, and adapt to the expectations of a college classroom.

FGC students often develop a fear in talking about themselves with their peers or their teachers and this creates a powerful dialectic which ultimately speaks to a students fear of judgment from others and interferes with their confidence in locating someone whom they could safely communicate with, as such, institutions must focus on creating trusting relationships with FGCs (Lowry-Hart \& Pacheco Jr., 2011). One place these trusting relationships can begin to develop is in the classroom, by inviting a more inclusive and less competitive space. Building trust can largely beneficial in the classroom, if students trust their teachers they may be more receptive to course content and participate in discussions, they may also make a larger effort in class if they feel their teachers care about them.

Compassionate communication, or critical compassionate pedagogy, offers ways in which instructors can help students gain a clearer understanding of expectations in the classroom as well as by building trust within the classroom. This type of communication also provides a framework for how educators can resist classism in the classroom. By being more aware of their actions, instructors can begin to create meaning in the classroom by developing spaces for inclusive learning environments, and becoming resources for students and agents for the transformative power of education. Rosenberg's (2003) compassionate communication framework "is founded on language and communication skills that strengthen our ability to remain human, even in trying 
conditions" (p. 3); these skills invite instructors to carefully examine and recognize behaviors that affect the communication in the classroom. Rosenberg reminds instructors that this is a process, a pedagogical strategy, and it is not meant to evolve overnight. Hao (2011) asserts that critical compassionate pedagogy "is not the only pedagogical framework that can be used to help FGCs succeed academically" (p. 93), but instructors can use it as a way to engender non-violent, compassionate communication with students and serve as a way to enhance the academic experiences of FGC students.

Critical compassionate pedagogy challenges instructors to reflect on their performances in the classroom and perhaps see the importance of being critical towards the inequality of college classrooms and move toward a more inclusive and accessible dialogue between students and teachers (Hao, 2011). While the teachers' role in this pedagogy is vital in order for the process to manifest, it is also a shared experience between teacher and student where each are often engaged in dialogue. In classrooms as diverse as SJSU's, it is of the utmost importance for instructors to value cultural differences and embrace diversity, not just cultural diversity but also racial/ethnic or gender diversity in students who have not traditionally attended college, including those of socioeconomic diversity. These differences play a large role in students' educational journeys, and if students and teachers can work together to create a more inclusive pedagogy, then FGC students may see more success in the classroom. Instructors may also experience a greater feeling of satisfaction with the learning of marginalized students who would normally face significant challenges in their classrooms. Critical compassionate pedagogy is about an instructor's critical engagement in the education process of FGCs; instructors often do not realize that education systems have failed many 
students from the start, and educators must be willing to help their students in any way that they can (Hao, 2011, p. 98).

Some of the FGC students I interviewed recalled times where they felt challenged in college classrooms, but also felt that they were being challenged because the teacher cared about their future and saw ability in them that they did not see in themselves. Claire feels that she benefited as an FGC student in a few of her classes because her teachers expressed their appreciation for having her in their class and they pushed her more and encouraged her to persevere. Chuck shared his experience from an introduction to psychology class that he was enrolled in, the class had a community feel and students felt like they were just as much a part of the class as their teacher was: "it was a really close nit class, I felt like I benefited by going to it and I actually go to learn in school." I suggest that teachers work with their students to create an inclusive space. If you work with your students you are inviting an opportunity to build trust with your students, build a community in your classroom and stimulate larger class discussions by empower students to play a larger role in their educational development.

While the role educators play in a student's education is monumental to their success, it is also important to call attention to the university systems and the ways in which their contribution to students experiences also plays a role in the overall experiences of both students and teachers. However, there is so much more that we can explore, and FGC students, faculty members, and universities could gain greater knowledge about this topic with additional research. The dialectic of autonomy versus connectedness indicates that understanding the experiences of FGC students in the classroom and the reasons why access to navigating the university is important for these 
students shows how these two factors play such a large role in students' ability to succeed in higher education. This information is valuable because it provides insight into the lives of students and knowledge that can improve university programming and enhance classroom dialogue.

\section{Implications and Recommendations for Researchers}

At the onset of this research I was optimistic in thinking that I could take on everything that I wanted to offer current FGC research and put it all into one study. In the process of doing this, I began to realize that this is one study, one of many, and while I intend to add to current dialogue, I also realize that I have yet to find a single comprehensive reference manual for FGC students that encompasses everything they need to know. So while I offer this study as a way to advance current research, I am also reminded that there is still much to do. My work as a graduate student has largely been informed by the expertise of professors and colleagues who are further ahead in the program than I am. While I began research for this study, I was surprised by the amount of FGC students in my department, both professors and students. I did not expect this, and I was happy to see that others have succeeded in following their educational dreams. As I look around at those who also make up the FGC student community at San José State University, I appreciate the diversity that each person brings. I am also reminded that we all come from different backgrounds; we all have different realities as FGC students, and yet, we are all counted the same when it comes to enrollment into universities. But, how can this be? How can an institution view a FGC student with considerable cultural capital and a FGC student who is low-income and placed in an EOP program as the same student? How do we differentiate student identity when counting 
FGC students? It is this type of system that places these students into universities without the necessary tools to succeed and then bases calculations on retention rates. And yes, knowing this, I have yet to find a large body of research that looks at the differences between these student bodies.

This research study serves as a place for me to reflect on my experiences and gain a better understanding for the experiences of others. My intent is not to point out what is wrong with current investigations, or insinuate that my approach is best, rather my goal is to invite more inclusive dialogue within instructional communication research. By including the experiences of other FGC students, I am able to share a larger representation of their voices in hopes my study can enrich our discipline and gain a more in depth understanding of how FGC students negotiate multiple identities in relation to dialectical tensions. There is still so much we can learn about what it is like to be a FGC student and what the communication needs of FGC students are.

There are numerous benefits to focus group research; for example, I am able to examine individual experiences of a diverse grouping of FGC students. These interviews provided a glimpse into the lives of FGC students, the kinds of tensions they face, and the strategies they use to both overcome difficulties and strive towards success. When I asked each focus group what advice they would give to current or future FGC students, three factors emerged. I will discuss each of these factors and provide examples of guidance for how to navigate tensions that emerge when trying to meet university expectations.

Through focus group interviews, I have presented the voices of FGC students in my research; however, the number of participants in my study is, in some ways, a 
limitation. After completing four focus group interviews, my research drew conclusions from sixteen FGC students. While this number is small, my intent was to gain illumination from the experiences of FGC students without generalizing about all FGC students. My research extends what communication studies scholars already know and offers a nuanced way of understanding this population of students because it highlights their particular perspective from their point of view.

Another limitation to this study is that my focus group interviews consisted of a mix of first generation undergraduate students and first generation graduate students, and this makes it hard to determine the differences between the challenges students face as the first in their family to enter college and the challenges being the first in the family to pursue both graduate and undergraduate degrees. In completing my study, I discovered several others ways in which research on FGC students could grow and develop. One way would be to understand the difference between FGC students who are connected with the Educational Opportunity Program (EOP) on campus and FGC students who do not have access to EOP because they do not qualify due to their income status. I see great benefit in understanding the ways in which students with access to EOP negotiated campus compared with those who did not utilize or have access to EOP. This benefit could provide a greater understanding for the need of this type of on campus resource for all FGC students, regardless of social class standing. On campus programs, such as EOP are a value to students and teachers because they provide students with a sense of know how around the campus, they hold students accountable for their studies and they provide mentorship to students who may have questions about the classroom but have yet to establish a working relationship with their teachers. 
Without the proper tools, success is not always possible. I wondered how so many FGC students felt as though they were being set up for failure in the classroom and exactly what the university does with the information after they report their percentage of FGC students on campus. I wanted to take my research beyond looking at the experiences of FGC students; instead, I longed for a greater examination into the lives of these students. I needed to see the individuals behind the statistic, and I wanted to understand how their identities play a role in their realities, how other FGCs were finding ways to succeed, and which ones were going unnoticed by the university, I hope my research will help other FGC students, by offering them a compassionate perspective. And, while my experiences may differ from theirs, I see room for improvement in higher education in relation to the treatment of FGC students. They do not need to feel alone. My goal is to offer up this study as a way to inspire others as well towards future research, as well as provide FGC students with a guide to help learn from the mistakes of others and perhaps it can also be a tool for growth in those times when it seems like no one else could possible relate to their journey. I trust that this will enrich current conversation and offer insight towards the direction of future conversations.

In order to create stories of success for and with FGC students, it is important to recognize the absence of discussion on the intersections of race, gender, sex, age, and ability in current dialogue on first generation college students, specifically when universities are counting these students. In other words, this isn't just a matter of including more inclusive identity, but rather recognizing how these identities work together to create lived experiences. Recognizing and acknowledging these intersections can inform content of future dialogue on an issue that is as complicated as the definition 
of what exactly constitutes a first generation college student; such rhetoric also contributes to confusion surrounding the ways in which universities report head counts on these students. Lowry-Hart and Pacheco (2011) assert that institutions of higher education face an important challenge; they must admit the their relationship with FGC students is insufficient and universities must also make a sincere attempt to develop and maintain such relationships. "It is not an easy process, but it is a necessary one" (p. 66).

\section{Implications and Recommendations for First Generation College Students}

Dialectical tensions emerge in communication in our interactions with family, friends, co-workers, partners, and peers. Relational dialectics theory suggests that relationships are a give and take process in constant motion (Lowery-Hart \& Pacheco Jr., 2011). Dialectical tensions are a give and take, it can feel painful in the beginning however, learning to manage these tensions, or resolve them, it what helps us feel whole again. The goal is to reframe/accept these tensions, so we don't have to feel they are pulling us apart. Lowery-Hart \& Pacheco Jr. (2011) tell us that, for FGCs, the give and take nature of their relationships are a result of their desire to maintain their cultural identity. While learning how to navigate college, these desires spark dialectical tensions as students learn how to live in the unknown and find a tenuous stability in the ebb and flow of higher education. When learning to live in the ebb and flow, it is important to acknowledge the ways in which access to navigating higher education plays a role in the success of FGCs in higher education.

In response to my second research question, I found that there are several tensions that contribute to whether or not an FGC student feels that $\mathrm{s} /$ he has received the tools to succeed in college. While there is a struggle in managing our cultural identities without 
college identities, there is also a tendency to struggle with feelings of who we are outside of a classroom because that becomes a culture all in its own. FGC students often isolate themselves in fear of losing their personal identity (Lowery-Hart \& Pacheco Jr., 2011). While there is a temptation to hold on to cultural identities, students often have to shift focus away from their identity as first generation in order to become fully immersed in college culture (Lowery-Hart \& Pacheco Jr., 2011). This is not to say that FGC students need to deny their status as such; instead they can situate themselves at the margins of known and unknown, acknowledging frustration at not having access while also accepting that self-exploration and navigation are often necessary in order to grow as people and as students.

The most important take away from this study, and from exploring FGCs through the lens of relational dialectics theory, is the understanding that it is completely acceptable to live in a liminal space. There is a great deal of pressure on FGC students, and it would serve them well to know that their experiences, challenges, and accomplishments are all part of the process; they do not need to choose one identity over another, and they do not need to decide between the tensions they face. As with many FGC students, interview participants provide examples of the ways in which they rely on strategies to manage tensions as they emerge. We must also find a strategy that allows us to be kind to ourselves, remembering that each of us is one person, and encourages us to accept that we can only accomplish so much in a day. One of the greatest lessons I took away from these interviews is realizing that my experiences, my frustrations, and my tensions are not unlike these of any other FGC student; what is different are our coping mechanisms. Strategies like balance and segmentation, spiraling inversion, and 
integration, manage different types of tension and offer ways to understand that, at times, some tensions will require more attention than others, but at no point do we have to make a choice between the two.

Learning how to navigate the university as a FGC student was a tumultuous task at times; however my perseverance proved worthwhile: I am now able to look back and remember everything I went through to get to this point and make peace with why it proved so difficult at times. In addition to learning how to gain access to necessary resources to succeed in higher education, I began to realize that I did not know the stories of other FGC students, and I found myself wanting to learn more about their journeys. I wanted to know how they also learned to navigate the university and manage the dialectical tensions that often arise from being the first in their families to attend college. As I searched for research on this topic, I realized that there is very little information regarding FGC students, especially within the field of communication studies.

Often, as FGC students, we want to take pride in our identity as such, though we may remain hesitant to share our identity with others for fear of judgment; at times, we want to feel independent and experience the rigor of college on our own, while, at other times, we express deep feelings of loneliness as we long for social support. Some experience feelings of oppression that manifest when they feel silenced, and there are others who experience a kind of privilege that no one else in their family has ever been able to achieve, and, with that, comes great pressure to succeed. In the midst of all this, we must find time for school, for work, for families, for friends, and for ourselves. More often than not, we negotiate our personal lives outside of school (i.e., work, friends, family) as a way to make room for the other. However, if we can appreciate what Baxter 
and Montgomery (1996) describe as "'both/and' status" (p. 6), we can feel a greater sense of accomplishment in living amongst the tensions instead of resisting, avoiding, or trying to resolve them.

Building community through social support. There were times in college that I questioned my ability to succeed. I wondered if I was up to par with the other students in my classes, and I did not know if anyone else was experiencing the tensions I faced as a first generation college student. It was not until the last year of my undergraduate work that I realized the value in making strong connections with my peers and instructors. Almost every FGC student who participated in the focus group interviews told me that they wished they had learned earlier on the importance of developing relationships with other FGC students. Many stated that they often do not disclose their FGC identity, stating that this came at a risk because they might not know whom to trust. This understandable reticence make relationship formation difficult, and FGC students often feel alone or isolated. Lola would have liked to have a mentor who was also a FGC student; Rosie would have also liked to receive more support and knowledge that she was not alone, observing that "there are so many moments in [college] where you feel so unsure of yourself, and you feel like the world is against you." For many of the FGC students I interviewed, locating social support and building a community were powerful tools for success, creating relationships that will likely continue after they graduate.

Creating a community offers numerous benefits, including establishing a space for students to share and discuss their struggles with one another. There have been several moments in college, both as an undergraduate and graduate student, where I just needed someone with whom I could talk. I could not go to my family or friends, and I 
did not want to burden any faculty members with my struggles. I just needed someone to listen and to tell me that I was not alone. This is something that I was fortunate enough to find within my graduate program cohort. We have spent many nights after class at Flames Restaurant discussing struggles, tensions, and what we could do to manage them. These nights also served as a reminder to myself and other students that we don't always need to push ourselves so hard; there is a great deal of self care that is required in college, and if you do not have a community of peers to remind you of this, it can often become to overwhelming and lead to burn out.

First generation college students must build a community with one another; without this support, we will have no one to share our stories with, no one to call at 3AM to ask why the paper that is due in the morning is not writing itself. These interviews acted as a community forum where FGC students could share their experiences and hear the experiences of others. It is imperative to network with your cohort so that you can have an outlet, outside of the walls of a classroom to express yourself, voice your frustration and celebrate victories, no matter how large or small. These are the kinds of support that you will need and this is often learned, and for some students it is after they have suffered unnecessarily, wondering if they were alone.

\section{Building relationships with faculty through mentorship. I was never}

comfortable speaking with my professors face to face; I would much rather connect through email. This developed into a pattern for me until I was a junior or senior; sadly, it took me that long to realize that my instructors are real people. They have lives outside of the university and to my delight, they are also still learning, still in process as people and as teachers. When I realized this, my life as a college student changed. I began to 
make connections with my instructors and, as a result, I became more passionate about my studies. I suddenly found myself wanting to succeed because I disappoint my teachers. The stakes became higher because they were not just my teachers anymore; some of them became mentors to me, and I still have connections with many of them. Two of my undergraduate professors wrote letters of recommendations for me when I applied to graduate school. This would not have been possible if I had not taken the time to make connections with them.

Many of us FGC students do not enter college with mentors. We are often not assigned a counselor, and we are unsure of reaching out to the teachers with whom we might make connections. This means that, like most experiences in college, we are on our own. We have to figure out to whom we are going to reach out, with whom we are going to make connections. This can be very difficult as an undergraduate FGC student because most of what we know about college we learn from reality TV, sitcoms, or movies where the focus in college is more about creating a social circle and less about getting to know our instructors. Without a explicit guidance, it can be difficult to know what expectations are in the university, and it is even more difficult to understand that your teachers want to make connections with you too. Renee explains that having a mentor would have changed his entire college experience because he would not have made so many mistakes. He also discusses the value of grades and the impact negative grades will have on your overall college experience.

In the focus group interviews, I learned that many students received less than satisfactory grades on assignments because they did not know to go to their instructor's office hours or ask for help with their grades. Too often, students suffer in silence over 
their grades, greatly affecting their ability to succeed. I suggest making connections with your instructors, speaking with them about any struggles you are having, and if you are not comfortable asking questions in class, utilizing their office hours. More often than not, your teachers are willing to help, but it takes work on the students' end as well, and taking the first step can lead you to a lasting mentorship.

Building confidence by exploring campus recourses. I recognize that the focus group participants noted a lot of what is not accessible to FGC students on campus. However, there are students who have received assistance from the university and who have been involved with on-campus programs. For these students, utilizing those resources was one factor in their ability to succeed in college thus far. Charles utilizes the resources offered by Associated Students on campus and where he can get assistance and gain more knowledge about the services the university provides. Finding an advisor early on is also a good idea. Since the university does not assign advisors upon admission it is worthwhile to locate someone within academic services with whom you feel comfortable working. Finding a counselor gave some participants access to tools and resources that they would have otherwise not known. These resources also build confidence in students because they feel more prepared and equipped for college.

A select group of students, usually those who are FGCs and are low income, enroll in a program called the Educational Opportunity Program, or EOP. For Ashley, EOP was extremely helpful; the program helped her manage her college experience so that she did not have to feel like she was on her own. Other on campus opportunities include: first generation college student workshops and support groups, an annual family 
night for first generation college students, and a plethora of other resources listed online under student' counseling services.

While there are resources on campus for FGC students, the most difficult aspect of building confidence is learning how to locate opportunities (e.g., how to apply for financial aid and scholarships, how to register for classes, how to receive a late drop from a class). If a student does not live on campus or work for the university (or know someone who does), it can be very discouraging to try to seek out assistance, especially if $\mathrm{s} / \mathrm{he}$ is not even aware that such programs exist. The universities are not always transparent about on-campus programs. As a graduate student, I only recently learned about many of the opportunities available to FGC students, and that is largely due to my interest in gaining a more clear understanding of how FGC students navigate the university. I learned a great deal about many of the programs during the focus group interviews, but I also became acutely aware that, like me, many FGC students do not even know such programs exist. Orlando reminds us that getting in college is the difficult process, but once you are in, its easy as long as you have what you need to feel confident enough to succeed. Know that being admitted to college speaks to your potential as a student and person. Wednesday wants all FGC students to keep their heads up and know that it is hard, but you will feel so much more empowered being an FGC student because you likely struggled and fought along the way. It can be a really powerful tool to be able to think for yourself and be successful no matter what obstacles are put in your way.

Making connections with classmates and networking is also a great way to gain confidence. You can't learn the answer if you don't ask the question. Utilize the 
knowledge of your peers or other students who may be a year ahead of you. Remember that, as students, we all start somewhere, and for many, it is at the bottom of the chain, but, with time, you will make your way to the top. Keith challenges students to think about the difference between themselves and other students, "think about the difference between you and others, there is no difference, it is all the same, be confident."

Campus resources can be a great way for students to confidence however, there is a disconnect between the university administration and the students; which can make it difficult for students to be confident in their ability to succeed when the institution they attend does not provide them with essential information on how to navigate college. Amanda suggests that all FGC students search for registration, orientation, and financial aid information prior to being admitted to the university; while it might prove challenging, you have to persevere because in most cases, it will not be provided to you. Part of the process of building confidence within yourself means believing that you can and will succeed if you put in the work. Finding a give and take between the predictability and novelty dialectic depends a great deal on whether or not you seek out the assistance you need. Take advantage of your teachers' office hours; ask questions when you can, and seek out mentors whenever possible. And, if you hit a roadblock; try not to feel defeated, be confident in yourself, and know that there is assistance out there.

If you are a current FGC student or FGC student alumni, offer your knowledge to fellow FGC students. Remember that professors cannot do everything. There is often a barrier in status between teacher and student, creating a space where students may not feel comfortable approaching their teachers, even if the teacher has done everything in their power to offer assistance to the students. As a part of a classroom culture, you can 
build community by reaching out and making connections with other students. You have a wealth of knowledge that first or second year FGC students may not have yet. If you see a student struggling in a class or if you are aware than another student in your cohort might also be an FGC, reach out to them, guide them through the process and ask if they have any questions. You might be surprised at how receptive another FGC student may be to you. We need to care for one another, be supportive and share what we know. We need to do our part in helping to ensure that FGC student attrition rates improve. If you can share your knowledge with one student, you could be changing the lives of many. The more we talk with one another, we can create inclusive dialogue and a culture of students who are no longer in the dark about what is means to succeed in college. The more relationships we build with one another, with non FGC students, and with faculty, the closer we will get to bridging the gap between success and failure in higher education.

\section{Final Thoughts}

I don't recall the particular details of the event, but I recall the location, and I remember feeling nervous and hopeful that I could make some connections with people at this orientation to the program. As I entered the classroom that housed many faculty members and fellow newly admitted students, it hit me; I was officially in graduate school. While I had yet to experience this in a classroom setting, I was still very much aware of this new identity, and while I shook the hands of numerous faculty members, I silently hoped that they would find that I was a right fit for the program. It all started with wanting to prove myself, wanting to play the role of graduate student, without actually knowing what that was. This experience was intimidating at best, but it was also orientation, the only one that I would have. My appreciation of this experience was 
something I could not express at the time; I am sure I looked overwhelmed and unnecessarily nervous. I am sure to others I seemed frightened.

Most of what I examine in this study are direct experiences of FGC students who, like myself, did not have a frame of reference for higher education. However, what I discovered in the end is that we are all students, and regardless of our status, we all face struggles; dialectical tensions are not reserved for FGC students, they are a vital part of college and life in general. It is important to remain compassionate towards others, regardless of ability, class, race, gender, and sex, because these are the people who will offer you support when you feel like no one else can, and these are the people who will reach out to you, motivate you, and sit with you in those moments when it all seems too much. As I look back on this moment, I wish I could tell myself what I know now; I wish I could tell myself that these people in the room are my allies, these are the people I will reach out to when I am in need of social support.

\section{Epilogue}

I still struggle with finding ways to relate to those who have not attended graduate school, specifically those who are not first generation students. I struggle to answer their questions because I feel like they don't understand where I am in my life and why I have chosen this path. It has been three years since I started this program, and I am still asked if I have homework this weekend or when my thesis will be done, and my answers never change indeed, I become so bothered by these questions that I find my responses come across quite terse at times. Don't they know this is a fulltime commitment? Of course, I have homework this weekend, and no, my thesis is still not done! I have a difficult time understanding why the questions keep coming. While these feelings arise, I must stop to 
remember that, prior to attending graduate school, I was that person asking the questions; I had very little understanding of what it was like to be in graduate school, let alone as a FGC student, until I attended my first graduate seminar. It was unfamiliar, intimidating, and I knew at that moment I was in the right place. So while I experience feelings of frustration in my perception of others' inability to relate to my journey, I am also reminded that it was not so long ago that I did not belong to this community. Acceptance is something that I have had to learn to embrace; I have learned to accept that this is a culture that many are unfamiliar with, and it is a culture that stimulates curiosity in people who may deep down wish they had taken the opportunity to pursue higher education or maybe just want a glimpse into what it entails.

There will come a time when the questions stop, when I will no longer be writing a thesis, and I venture to guess I will have more time in life to just be. But, what I won't have is the community that I have built around me over the last three years; I will not have the comfort of college classrooms that were once so daunting, and I will no longer have the identity of student, I will always be a learner in some capacity. I remind myself about the importance of not forgetting where I come from. I will never regret my decision to embark on this educational journey, but regardless of where I end up in life, I would not be where I am today if it were not for the unwavering support of my family, friends, colleagues, and mentors, and for this, I am eternally grateful. 


\section{References}

Baxter, L. A. (1990). Dialectical contradictions in relationship development. Journal of Social and Personal Relationships, 7, 79-88.

Baxter, L. A. (2004). A tale of two voices: Relational dialectics theory. The Journal of Family Communication, 4,181-192.

Baxter, L. A., \& Montgomery, B. M. (1996). Relating: Dialogue and dialectics. New York: Guilford.

Berger, M.T., \& Guidroz, K. (2009). The intersectional approach: Transforming the academy through race, class, and gender. Chapel Hill, NC: The University of North Carolina Press.

Billson, J.M., \& Terry, M.B. (1981). In search of the silken purse: Factors in attrition among first generation students. Presented to the Annual Meeting of the Association of American Colleges, Denver, CO.

Brooks-Terry, M. (1988). Tracing the disadvantages of first-generation college students: An application of Sussman's option sequence model. In S. K. Steinmetz (Ed.), Family support systems across the life span (pp. 121-134). New York, NY: Plenum Press.

Collins, P.H. (1998). Fighting words: Black women and the search for justice. Minneapolis: University of Minnesota Press.

Davis, J. (2010). The first-generation student experience: Implications for campus practice, and strategies for improving persistence and success. Sterling, VA: Stylus Publishing.

Fassett, D. L., \& Warren, J. T. (2007). Critical communication pedagogy. Thousand Oaks, CA: SAGE.

Fassett, D. L., \& Warren, J. T. (2005). The strategic rhetoric of an "at-risk" educational identity: Interviewing Jane. Communication and Critical/Cultural Studies, 2(3), 238-256.

Flick, U. (2007). Designing qualitative research. Thousand Oaks, CA: SAGE.

Freire, P. (1970/2000). Pedagogy of the oppressed. New York: Continuum.

Goodall, Jr., H. L. (2000). Writing the new ethnography. Lanham, MA: AltaMira Press.

Hao, R. N. (2011). Reading critical pedagogy: Implications on silence and silent bodies. Text and Performance Quarterly, 31(3), 267-284. 
Hao, R.N. (2011). Critical compassionate pedagogy and the teacher's role in first generation student success. In T. Heinz-Housel, \& V. L. Harvey (Eds.), Faculty and first generation college students: Bridging the classroom gap together (pp. 55-68). San Francisco, CA: Wiley Periodicals, Inc.

Hennings, J. M. (2009). Tales of teaching: Exploring the dialectical tensions of the GTA experience. (Unpublished masters thesis), San José State University. San Jose, CA.

hooks, b. (2003). Teaching community: A pedagogy of hope. New York: Routledge.

hooks, b. (1994). Teaching to transgress: Education as the practice of freedom. New York: Routledge.

hooks, b. (2000). Where we stand: Class matters. New York: Routledge.

Heinz-Housel, T, \& Harvey, V.L. (2009) Introduction and overview of book's objectives. In T. Heinz-Housel, \& V. L. Harvey (Eds.), The invisibility factor: Administrators and faculty reach out to first generation college students (pp. 2333). Boca Raton, FL: Brown Walker Press.

Kvale, S. (2007). Doing interviews. Thousand Oaks, CA: SAGE.

Lancaster, C.M. (2010). First-generation college students, graduate school, and social support. (Unpublished masters thesis). San José State University, San Jose, CA.

Lawless, B. (2009). Guiding class consciousness in first generation college students. A pragmatic approach to classism in the academy. In T. Heinz-Housel, \& V. L. Harvey (Eds.), The invisibility factor: Administrators and faculty reach out to first generation college students (pp. 23-33). Boca Raton, FL: Brown Walker Press.

Lindlof, T. R., \& Taylor, B. C. (2002). Qualitative communication research methods (2nd ed.). Thousand Oaks, CA: SAGE.

Lorber, J. (2005). Gender inequality: Feminist theories and politics. Los Angeles, CA: Roxbury Publishing Company.

Lowry-Hart, R., \& Pacheco Jr., G. (2011). Understanding the first generation student experience in higher education through a relational dialectic perspective. In T. Heinz-Housel, \& V. L. Harvey (Eds.), Faculty and first generation college students: Bridging the classroom gap together (pp. 55-68). San Francisco, CA: Wiley Periodical, Inc.

Madison, D. S. (2005). Critical ethnography: Method, ethics, and performance. Thousand Oaks, CA: SAGE. 
McLaren, P. (1993). Schooling as a ritual performance: Towards a political economy of educational symbols and gestures (2nd ed.). London: Routledge.

McCracken, G. (1988). The long interview. Newbury Park, CA: SAGE.

Nainby, K., \& Pea, J.B. (2003). Immobility in mobility: Narratives of social class, education, and paralysis. Educational Foundations, 17, 19-36.

Orbe, M.P. (2004). Negotiating multiple identities within multiple frames: An analysis of first-generation college students. Communication Education, 53, 131-149.

Orbe, M.P., \& Groscurth, C.R. (2004). A co-cultural theoretical analysis of communicating on campus and at home: Exploring the negotiation strategies of first generation college (FGC) students. Qualitative research reports in communication, 4, 41-47.

Prentice, C. M., \& Kramer, M. W. (2006). Dialectical tensions in the classroom: Managing tensions through communication. Southern Communication Journal, 77(4), 339-361.

Putman, A. \& Thompson, S. (2006). Paving the way: First-generation Mexican American community college students in a border community speak out. Intercultural Communication Annual, 29, 121-142.

Rosenberg, M.B. (2003). Nonviolent Comminicaiton: A language of life. ( $\left.2^{\text {nd }} \mathrm{ed}.\right)$. Encinitas, CA: PuddleDancer Press.

Rosenfeld, L.B., \& Richman, J.M. (1999). Supportive communication and school outcomes, part II: Academically "at-risk" low income high school students. Communication Education, 48, 294-307.

Rosenfeld, L.B., Richman, L.B., \& Bowen, G.L. (1998). Supportive communication and school outcomes for academically "at risk" and other low income middle school students. Communication Education, 47, 309-325.

Simpson, J. S. (2003). I have been waiting: Race and U.S. higher education. Toronto, Canada: University of Toronto Press.

Speirs, K.L., \& Rinker, J. (2006). An emerging professional identity: Influences on the achievement of high-ability first-generation college females. Journal of the Education of the Gifted, 29(3), 305-338.

Stewart, D.W., Shamdasani, P.N., \& Rook, D.W. (2007). Focus groups: Theory and practice. Thousand Oaks, CA: SAGE. 
Turner, V. (1987). Betwixt and between: The liminal periods in rights of passage. In L.C. Madhi (Ed.), Betwixt and between: Patterns of masculine and feminine initiation (pp. 3-19). Peru, IL: Open Court Publishing Company.

Weber, L. (2006). Understanding race, class, gender, and sexuality: A conceptual framework. Boston, MA: McGraw-Hill College. 


\section{APPENDIX A: IRB Approval to Conduct Research}

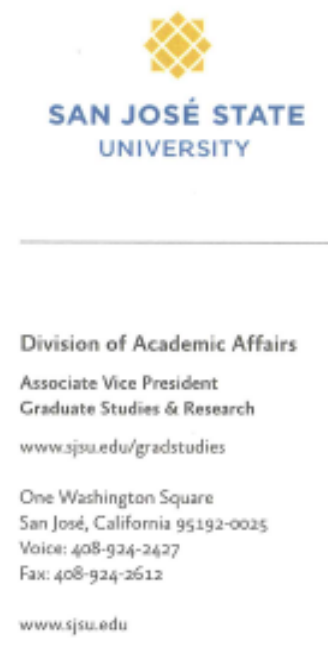

To: Laurina Lanham

From: Pamela Stacks, Ph.D.

Associate Vice President

Graduate Studies and Research

Date: March 7,2012

The Human Subjects-Institutional Review Board has approved your request to use human subjects in the study entitled:

"Beating the odds? An analysis of first-generation identity in intersectional academic contexts"

This approval is contingent upon the subjects participating in your research project being appropriately protected from risk. This includes the protection of the confidentiality of the subjects' identity when they participate in your research project, and with regard to all data that may be collected from the subjects. The approval includes continued monitoring of your research by the Board to assure that the subjects are being adequately and properly protected from such risks. If at any time a subject becomes injured or complains of injury, you must notify Dr. Pamela Stacks, Ph.D. immediately. Injury includes but is not limited to bodily harm, psychological trauma, and release of potentially damaging personal information. This approval for the human subject's portion of your project is in effect for one year, and data collection beyond March 7,2013 requires an extension request.

Please also be advised that all subjects need to be fully informed and aware that their participation in your research project is voluntary, and that he or she may withdraw from the project at any time. Further, a subject's participation, refusal to participate, or withdrawal will not affect any services that the subject is receiving or will receive at the institution in which the research is being conducted.

If you have any questions, please contact me at (408) 924-2427.

Protocol \#S1202060

cc. Deanna Fassett $\quad 0112$ 


\section{APPENDIX B: Agreement to Participate in Research}

\section{8 \\ SAN JOSÉ STATE UNIVERSITY}

\footnotetext{
College of Social Sciences Department of Communication Studies

One Washington Square Sun José, Callfornia 95192-0112 Voice: (405) 924-5360 Face (408) $924-5396$ Email: commesisuedu wwws.spu.edu/comm

wwwsplpuedu
}

\begin{abstract}
Letter of Consent for Adults
Responsible Investigator: Laurina J. Lanham

Title of Protocol: Beatings the odds? An Analysis of FirstGeneration Identity in Intersectional Academic Contexts

1.) I am a student under the direction of Dr. Deanna Fassett in the Communication Studies Department at San José State University. You have been asked to participate in a research study investigating the ways in which students negotiate dialectical tensions of identity in the college classroom.
\end{abstract}

2.) You will be asked participate in 1 focus group interview (lasting approximately 90 minutes) with Laurina Lanham at times, dates and locations that are mutually convenient; these interviews will be audio taped.

3.) During the interviews, you may choose to reflect on personal experiences that are challenging or uncomfortable. You may also benefit from having the opportunity to share reflect and share your experiences as a member of this community.

4.) While the results of this study may be published, any information that could identify you will be removed from the final document, or in any file, notes, or subsequent papers.

5.) While your participation is appreciated, you will not receive monetary compensation for participation in this research study.

6.) Questions about this research may be addressed to Laurina Lanham, (408) 250-6982, lilanham06@gmail.com, or Dr. Deanna L. Fassett, (408) 924-5511, deanna.fassett@sjsu.edu. Complaints about the research may be presented to Dr. Stephanie Coopman, Department Chair, Department of Communication Studies, (408) 924-5360. Questions about research subjects' rights, or a research-related injury, may be presented to Dr. Pamela Stacks, Associate Vice President, Graduate Admissions and Program Evaluations, (408) 924-2488.

7.) No service of any kind, to which you are otherwise entitled, will be lost or jeopardized if you choose to not participate in this study.

8.) Your consent is being given voluntarily. You may refuse to participate in the entire study or in any part of the study. If you decide to participate in the study, you are free to withdraw at any time without any negative effect on your relations with San Jose State University or with any other participating institutions or agencies.

9.) At the time that you sign this consent form, you will receive a copy of it for your records, signed and dated by the investigator.
- The signature of a participant on this document indicates agreement to participate in the study.
The signature of a researcher on this document indicate agreement to include the above named participant in the research and attestation that the participant has been fully informed of her or his rights.

\begin{tabular}{lll}
\hline Participant's Signature & Date \\
Investigator's Signature & Date
\end{tabular}




\section{APPENDIX C: Interview Protocol}

\section{RQ1: How do first generation college students communicate dialectical tensions in the classroom?}

1. Please describe yourself as a person and as a student.

2. How do you feel about being the first in your family to attend college?

3. Do you disclose your identity as an FGC student? If so, when and how?

4. Please describe some ways that your experience as a FGC student affects your communication in classrooms.

5. What are some challenges you face as a FGC student, whether in the classroom, at work, or at home?

6. Describe a time when you felt your status as a FGC student helped you in a college classroom.

7. Describe a time when you felt your status as a FGC student hindered you in a college classroom.

\section{RQ2: How does a first generation college student's access to navigating college contribute to success in higher education?}

8. What sorts of resources did you receive as a FGC student? What sorts of resources would you have liked to receive?

9. How did you learn how to navigate SJSU? Who or what was helpful to you?

10. What wasn't helpful to you in learning to navigate SJSU?

11. What mistakes did you make while learning how to navigate the university?

12. If given the opportunity to mentor a FGC student, what advice would you provide on how to navigate college?

13. Any final thoughts or reflections you'd like to share? 